\title{
BLAST screening of chlamydial genomes to identify signature proteins that are unique for the Chlamydiales, Chlamydiaceae, Chlamydophila and Chlamydia groups of species Emma Griffiths, Michael S Ventresca and Radhey S Gupta*
}

Address: Department of Biochemistry and Biomedical Sciences, McMaster University, Hamilton, Ontario, L8N 3Z5, Canada

Email: Emma Griffiths - griffie@mcmaster.ca; Michael S Ventresca - ventrems@mcmaster.ca; Radhey S Gupta* - gupta@mcmaster.ca

* Corresponding author

Published: 25 January 2006

BMC Genomics 2006, 7:14 doi:10.1186/147|-2164-7-14

This article is available from: http://www.biomedcentral.com//47/-2/64/7//4

(c) 2006 Griffiths et al; licensee BioMed Central Ltd.

This is an Open Access article distributed under the terms of the Creative Commons Attribution License (http://creativecommons.org/licenses/by/2.0), which permits unrestricted use, distribution, and reproduction in any medium, provided the original work is properly cited.

\begin{abstract}
Background: Chlamydiae species are of much importance from a clinical viewpoint. Their diversity both in terms of their numbers as well as clinical involvement are presently believed to be significantly underestimated. The obligate intracellular nature of chlamydiae has also limited their genetic and biochemical studies. Thus, it is of importance to develop additional means for their identification and characterization.

Results: We have carried out analyses of available chlamydiae genomes to identify sets of unique proteins that are either specific for all Chlamydiales genomes, or different Chlamydiaceae family members, or members of the Chlamydia and Chlamydophila genera, or those unique to Protochlamydia amoebophila, but which are not found in any other bacteria. In total, 59 Chlamydialesspecific proteins, 79 Chlamydiaceae-specific proteins, 20 proteins each that are specific for both Chlamydia and Chlamydophila and 445 ORFs that are Protochlamydia-specific were identified. Additionally, 33 cases of possible gene loss or lateral gene transfer were also detected.

Conclusion: The identified chlamydiae-lineage specific proteins, many of which are highly conserved, provide novel biomarkers that should prove of much value in the diagnosis of these bacteria and in exploration of their prevalence and diversity. These conserved protein sequences (CPSs) also provide novel therapeutic targets for drugs that are specific for these bacteria. Lastly, functional studies on these chlamydiae or chlamydiae subgroup-specific proteins should lead to important insights into lineage-specific adaptations with regards to development, infectivity and pathogenicity.
\end{abstract}

\section{Background}

The Chlamydiales are clinically important intracellular parasites and endosymbionts of eukaryotic hosts, and cause a wide spectrum of diseases in humans and animals [1]. Recently, the taxonomic classification of this group was revised and currently contains at least 4 distinct families (viz.Chlamydiaceae, Simkaniaceae, Parachlamydiaceae and
Waddliaceae) based on $>90 \% 16 \mathrm{~S}$ rRNA identity and a common developmental cycle $[2,3]$. While chlamydial infections are best known for the genitourinary, ocular and respiratory infections they cause in humans, the chlamydiae are also quite common in many wild and domestic animals with potential for severe zoonotic disease [4]. The newly described chlamydial species Simkania 
and Parachlamydia have also been found associated with human respiratory infections, while Waddlia has been implicated in abortion in bovines [5-7]. These revisions reflect important changes in perceptions regarding chlamydial diversity in line with recent discoveries of novel animal isolates (Waddliae and Simkaniae) and more strikingly of chlamydia-related endosymbionts or "environmental chlamydiae" (i.e. Parachlamydiae) infecting free-living amoebae [8-10]. Free-living amoebae, important components of soil and water ecosystems, are being increasingly recognized as vectors for various bacterial human pathogens $[4,7,11,12]$.

Species are currently recognized as belonging to the Chlamydiales according to 16S and 23S rRNA similarities and pathogenic traits [2]. As these organisms are antigenically and genetically diverse, it is important to develop additional means to identify and distinguish them unambiguously from all other bacteria. The intracellular nature of chlamydiae species has been a hindrance in understanding their genetics, physiology and development. Hence, other means that can provide some insight in these regards are needed. In recent years, the genomes of several chlamydiae species have been sequenced including five Chlamydiaceae members (viz. Chlamydia (Chl.) trachomatis, Chl. muridarum, Chlamydophila (Chlam.) pneumoniae, Chlam. caviae and Chlam. abortus [13-16] and the environmental chlamydiae species Protochlamydia amoebophila (Parachlamydiaceae) [11]. Until recently when the $P$. amoebophila genome (formerly Parachlamydia UWE25;[17]) sequence was released, the information for chlamydiae-like organisms was practically non-existent, and it was virtually impossible to establish a core set of genes that are common to various Chlamydiales species. The Protochlamydia genome $(2.41 \mathrm{Mb})$ was found to be about twice the size of various Chlamydiaceae species (1.04-1.23 Mb) and it showed a number of important differences including the presence of a complete TCA cycle and highly modified gene order [11]. The availability of these genomes has made it possible to carry out comparative studies. Horn et al. [11] reported 711 open reading frames (ORFs) or coding sequences that were shared among all chlamydiae genomes. However, many of these proteins have homologs in bacteria outside of the Chlamydiales and the proteins which were unique to only chlamydiae were not examined. Similarly, other studies which have determined proteins common to all Chlamydiaceae genomes also included peptides which were ubiquitous among bacteria [13-16]. While the work of Kalman et al. [18] revealed a number of potentially chlamydiae-specific genes, these studies were based on only 2 genomes, Chlam. pneumoniae and Chl. trachomatis, and the study was carried out when sequence information for other bacteria was limited.
Our recent work on comparative genomics is aimed at identifying novel and distinctive molecular characteristics of different groups of bacteria, including chlamydiae, which can be used for their identification, classification as well as genetic and biochemical studies [19-23] (see also [24]). We have recently described a number of molecular signatures consisting of conserved inserts and deletions (i.e. indels) in widely distributed proteins that are distinctive characteristics of all available chlamydiae species and are not found in any other bacteria [25]. In the present study, we describe a different kind of taxonomic marker, consisting of whole proteins that are specific for different groups of chlamydiae species, which provides additional powerful means for identifying these groups of species and for understanding their evolution as well as physiological characteristics. In this work, we have carried out systematic BLAST searches on all proteins or ORFs in the genomes of a number of chlamydiae species to compile profiles of proteins that are either uniquely shared by all Chlamydiales-species or particular subgroups (family or genera) within this phylum and can likely be used as distinct molecular markers for these groups. The study of these chlamydial group specific proteins should prove instrumental in the discovery of novel physiological characteristics that are uniquely shared by this important group of pathogens.

\section{Results}

The present study was undertaken to identify unique proteins (or ORFs) which are found in the chlamydiae species at various taxonomic depths. Kalman et al [18] have previously examined the presence of chlamydiae-specific proteins in 2 sequenced genomes, Chl. trachomatis serovar $\mathrm{D}$ and Chlam. pneumoniae. Their study documented a number of proteins such as EUO, Gp6D, IncsB/C, LtuA/B, a number of Pmps and hypothetical proteins, which were specific for these species. However, because the number of species examined was so small, it was unclear how broadly these proteins were distributed among different chlamydiae species. At that time there was also no sequence information for the proteins from any chlamydiae-like organisms. Thus, based on this earlier study it was unclear whether the identified peptides were distinctive of different Chlamydiales, or only particular subsets of chlamydial species [18].

In order to identify chlamydiae-specific genes/proteins that are present at different phylogenetic depths, each ORF from the Chl. trachomatis and Chlam. caviae genomes were individually BLAST searched against all available databases. These species were chosen in order that sequences from both the Chlamydia and the Chlamydophila genera were represented in the searches. Results of the BLAST searches were inspected to identify proteins where either all of the observed hits were from other chlamydial 
Table I: List of the Chlamydiales-specific proteins

\begin{tabular}{|c|c|c|c|c|c|c|c|c|}
\hline Protein Loci & $\begin{array}{l}\text { Protein (Name/ } \\
\text { Size) }\end{array}$ & C. tra & C. mur & C. pne & C. cav & C. abo & Protochlam. & $\begin{array}{l}\text { Next best BLAST Hit (E value, } \\
\text { protein length) }\end{array}$ \\
\hline СТ007 (AAC67597) & hypoth, $316 \mathrm{aa}$ & 0 & $8 e-164$ & $8 e-108$ & $6 e-108$ & $3 e-105$ & $8 \mathrm{e}-10,320 \mathrm{aa}$ & Plasmodium yoelii $(0.063,149$ laa $)$ \\
\hline CTOII (AAC6760I) & hypoth, $418 \mathrm{aa}$ & 0 & 0 & $7 e-|5|$ & $2 e-155$ & le-157 & 7e-47, 445aа & $\begin{array}{l}\text { Desulfotalea psychrophila (l e-06, } \\
\text { 337aa) }\end{array}$ \\
\hline СТ0I6 (AAC67606) & hypoth, 242aa & $2 e-139$ & $3 e-119$ & le-82 & $4 e-89$ & $3 e-86$ & $2 \mathrm{e}-37,233 \mathrm{aa}$ & Rickettsia sibirica $(0.20, \mathrm{I} 85 \mathrm{I}$ aa $)$ \\
\hline CT0I7 (AAC67607) & hypoth. 433aa & 0 & 0 & le- 122 & $7 e-133$ & $9 e-135$ & $4 e-52,43$ Iaa & $\begin{array}{l}\text { Thermo. tengcongensis (le-06, } 306 \\
\text { aa) }\end{array}$ \\
\hline CT02I (AAC676II) & hypoth, 247aa & $2 e-139$ & $4 e-107$ & le-47 & $3 e-56$ & $4 e-53$ & $2 \mathrm{e}-13,245 \mathrm{aa}$ & Xenopus laevis (I.7, 600aa) \\
\hline СТ03I (AAC6762I) & hypoth, 100aa & $4 e-5 I$ & $4 e-42$ & $2 e-25$ & $4 e-26$ & $2 e-26$ & $0.010,107 \mathrm{aa}$ & Mus musculus $(3.6,384 \mathrm{aa})$ \\
\hline СТ038 (AAC67628) & hypoth, II6aa & le-63 & $2 e-49$ & $4 e-25$ & le-25 & $2 e-23$ & $2 e-09,109 a a$ & Neurospora crassa $(2.8,1223 \mathrm{aa})$ \\
\hline СТ053 (AAC67644) & hypoth, I48aa & $2 e-6 I$ & $4 e-57$ & $2 e-5 I$ & le-50 & le-48 & $5 e-29,155 a a$ & Xenopus tropicalis (4.7, 1049aa) \\
\hline СТ066 (AAC67657) & hypoth, I58aa & $3 e-77$ & le-75 & $8 e-65$ & $3 e-65$ & $5 e-65$ & $6 e-41,165 a a$ & Vibrio parahaemolyticus $(1.8,92 \mathrm{aa})$ \\
\hline СТ079 (AAC67670) & hypoth, 147aa & $4 e-81$ & $|e-7|$ & $2 e-06$ & le-29 & Ie-29 & $3 e-06,172$ aa & $\begin{array}{l}\text { Leuconostoc mesenteroides ( } 0.11 \text {, } \\
\text { 263aa) }\end{array}$ \\
\hline CTI3I (AAC67722) & PTMP, I I38aa & 0 & 0 & 0 & 0 & 0 & $3 e-33,1348 a a$ & Plasmodium yoelii (0.31, 592aa) \\
\hline CTI8I (AAC67772) & hypoth, 236aa & $7 e-13 \mid$ & $|e-1| 3$ & $3 e-77$ & $7 e-81$ & $4 e-80$ & $2 \mathrm{e}-10,200 \mathrm{aa}$ & Acinetobacter sp. $(0.94,37 \mathrm{Iaa})$ \\
\hline CT260 (AAC67853) & hypoth, I63aa & $9 e-91$ & $9 e-81$ & $5 e-62$ & $3 e-68$ & le-67 & $4 e-22,159 a a$ & Sinorhizobium meliloti $(0.18,166 \mathrm{aa})$ \\
\hline CT266 (AAC67859) & hypoth, 393aa & 0 & $5 e-179$ & $9 e-103$ & $5 e-120$ & $2 \mathrm{e}-119$ & 4e-08, 498aa & $\begin{array}{l}\text { Xanthomonas axonopodis }(2.8, \\
\text { 189aa) }\end{array}$ \\
\hline CT27I (AAC67864) & hypoth, 95aa & le-39 & $2 e-36$ & $7 e-25$ & le-25 & $9 e-26$ & Ie-10, 97aa & Gibberella zeae $(3.6,1362)$ \\
\hline СT273 (AAC67866) & hypoth, I88aa & $2 e-89$ & le-77 & $2 e-60$ & $5 e-63$ & $2 e-63$ & $0.00 \mathrm{I}, \mathrm{I} 49 \mathrm{aa}$ & $\begin{array}{l}\text { Corynebacterium efficiens }(0.34, \\
640 \mathrm{aa})\end{array}$ \\
\hline CT274 (AAC67867) & $\begin{array}{l}\text { type III secretion } \\
\text { chaperone, I39aa }\end{array}$ & $3 e-74$ & $3 e-70$ & $|e-6|$ & le-62 & $|e-6|$ & $3 e-3|| 3 \mid$, aa & $\begin{array}{l}\text { Synechococcus elongatus ( } 2 \mathrm{e}-05 \text {, } \\
363 \mathrm{aa})\end{array}$ \\
\hline СТ303 (AAC67896) & hypoth, I7Iaa & $2 e-81$ & $5 e-66$ & $2 e-40$ & $2 e-47$ & $6 e-47$ & $3 e-04,177 a a$ & Yersinia pestis (I.3, 373aa) \\
\hline CT309 (AAC67902) & hypoth, 266aa & $2 \mathrm{e}-144$ & $2 e-129$ & $8 e-86$ & le-93 & $5 e-94$ & 2e-29, 263aa & $\begin{array}{l}\text { Methanococcus jannaschii (2.6, } \\
\text { 434aa) }\end{array}$ \\
\hline СТ3। 2 (AAC67905) & $\begin{array}{l}\text { pred. ferredoxin, } \\
\text { 123aa }\end{array}$ & $6 e-67$ & $6 e-54$ & le-30 & $7 e-36$ & le-35 & Ie-04, 130aa & Pan troglodytes (1.2, 1524aa) \\
\hline CT350 (AAC67945) & hypoth, 566aa & 0 & 0 & $2 e-|4|$ & $3 e-157$ & le-157 & $2 e-30,56$ laa & $\begin{array}{l}\text { Nostoc sp. PCC 7I20 (7e-06, } \\
\text { I547aa) }\end{array}$ \\
\hline CT35I (AAC67946) & hypoth, 697aa & 0 & 0 & 0 & 0 & 0 & $5 e-53,720 a a$ & Rattus norvegicus $(3.4,389 \mathrm{aa})$ \\
\hline СТ355 (AAC67950) & hypoth, 353aa & 0 & $3 e-161$ & $3 e-101$ & $8 e-101$ & Ie-102 & |e-2|, 375aa & $\begin{array}{l}\text { Chromobacterium violaceum }(0.82 \text {, } \\
556 \mathrm{aa})\end{array}$ \\
\hline CT384 (AAC67980) & hypoth, $539 a a$ & 0 & 0 & $9 e-106$ & $4 e-113$ & $|e-|||$ & $2 \mathrm{e}-14,580 \mathrm{aa}$ & $\begin{array}{l}\text { Pseudomonas fluorescens }(0.29 \text {, } \\
3 \mid 4 \mathrm{aa})\end{array}$ \\
\hline CT387 (AAC67984) & hypoth, 69 laa & 0 & 0 & 0 & 0 & 0 & $4 \mathrm{e}-160,740 \mathrm{aa}$ & $\begin{array}{l}\text { Rubrobacter xylanophilus (5e-10, } \\
263 \mathrm{aa})\end{array}$ \\
\hline CT42I.2 (AAC6803I) & hypoth, 53aa & $5 e-23$ & $2 e-22$ & $5 e-19$ & $7 e-20$ & $4 e-19$ & $2 \mathrm{e}-12,52 \mathrm{aa}$ & no other BLAST hits \\
\hline CT425 (AAC68022) & hypoth, 62 laa & 0 & 0 & 0 & 0 & 0 & 0,665 aа & $\begin{array}{l}\text { Bordetella parapertussis (4e-10, } \\
767 \mathrm{aa})\end{array}$ \\
\hline CT429 (AAC68026) & hypoth, 329aa & $4 e-165$ & $4 e-162$ & $5 e-149$ & $2 e-15 \mid$ & $7 e-151$ & $8 e-96,388 a a$ & $\begin{array}{l}\text { Geobacter sulfurreducens (2e-04, } \\
\text { I 46aa) }\end{array}$ \\
\hline CT443 (AAC68042) & OmcB, 553aa & 0 & 0 & 0 & 0 & 0 & $4 e-66,558 a a$ & Rhodopirellula baltica (3e-25, 907aa) \\
\hline CT446 (AAC68045) & $\begin{array}{l}\text { EUO protein, } \\
\text { I83aa }\end{array}$ & le-78 & $8 e-72$ & le-50 & $2 e-53$ & |e-52 & $4 e-41,139 a a$ & Magnaporthe grisea (2.1, 1259aa) \\
\hline CT474 (AAC68074) & $\begin{array}{l}\text { LysM protein, } \\
336 \mathrm{aa}\end{array}$ & $2 e-168$ & $9 e-116$ & $5 e-59$ & $9 e-71$ & $7 e-71$ & $3 e-04,482 a a$ & no other BLAST hits \\
\hline CT504 (AAC68I05) & hypoth, $288 \mathrm{aa}$ & $2 e-127$ & |e-105 & $4 e-64$ & $2 e-69$ & $2 e-68$ & Ie-23, 376aa & Mus musculus (3.0, 96laa) \\
\hline CT538 (AAC68।40) & hypoth, 238aa & $8 e-124$ & $1 \mathrm{e}-120$ & $5 e-105$ & le- 108 & le-108 & $9 e-65,244 a a$ & $\begin{array}{l}\text { Fritschea bemisiae }(3 \mathrm{e}-59,24 \mathrm{Iaa}) \\
\text { Enterococcus faecalis }(0.067,54 \mathrm{Iaa})\end{array}$ \\
\hline CT546 (AAC68I48) & $\begin{array}{l}\text { predicted OMP, } \\
289 \text { aa }\end{array}$ & $3 e-163$ & $4 e-157$ & $6 e-87$ & le-92 & le-93 & $3 e-23,249 a a$ & $\begin{array}{l}\text { Legionella pneumophila }(0.042 \text {, } \\
254 \mathrm{aa})\end{array}$ \\
\hline CT547 (AAC68I49) & hypoth, $318 \mathrm{aa}$ & $2 e-175$ & $7 e-158$ & $8 e-90$ & le-92 & $2 e-93$ & $8 e-29,468 a a$ & $\begin{array}{l}\text { Caenorhabditis elegans }(4 \mathrm{e}-04, \\
\text { II68aa) }\end{array}$ \\
\hline CT548 (AAC68I50) & hypoth, 194aa & $3 e-89$ & $2 e-67$ & le-48 & $2 e-49$ & $3 e-48$ & $0.004,185 \mathrm{aa}$ & $\begin{array}{l}\text { Drosophila melanogaster }(0.17, \\
826 \mathrm{aa})\end{array}$ \\
\hline CT556 (AAC68I58) & hypoth, 159aa & le-92 & le-82 & $9 e-59$ & le-60 & le-59 & $2 \mathrm{e}-06,157 \mathrm{aa}$ & Xenopus laevis (1.8, 1636aa) \\
\hline CT560 (AAC68162) & hypoth, 278aa & le-135 & $2 e-125$ & le-86 & $4 e-94$ & $5 e-93$ & $0.002,28 \mathrm{I}$ aa & no other BLAST hits \\
\hline CT573 (AAC68I75) & hypoth, 409aa & 0 & le-179 & $9 e-90$ & $3 e-113$ & $2 e-106$ & le-43, 472aa & $\begin{array}{l}\text { Pseudomonas syringae ( } 0.46 \text {, } \\
9376 \mathrm{aa})\end{array}$ \\
\hline
\end{tabular}


Table I: List of the Chlamydiales-specific proteins (Continued)

\begin{tabular}{|c|c|c|c|c|c|c|c|c|}
\hline CT583 (AAC68I85) & $\begin{array}{l}\text { Virulence plasmid } \\
\text { pGP6 related } \\
\text { protein, 263aa }\end{array}$ & $5 e-134$ & $6 e-118$ & $4 e-82$ & $4 e-91$ & $2 e-92$ & Ie-46, 245aa & $\begin{array}{l}\text { Crocosphaera watsonii }(0.036, \\
\text { 333aa) }\end{array}$ \\
\hline CT590 (AAC68192) & hypoth, 954aa & 0 & 0 & 0 & 0 & 0 & $8 e-96,989 a a$ & $\begin{array}{l}\text { Porphyromonas gingivalis }(0.003 \text {, } \\
645 \mathrm{aa})\end{array}$ \\
\hline CT602 (AAC68205) & hypoth, I30aa & $5 e-60$ & le-55 & $2 e-35$ & $3 e-37$ & le-37 & $2 \mathrm{e}-19,13 \mathrm{Iaa}$ & $\begin{array}{l}\text { Actinobacillus pleuropneumoniae } \\
(2.8,300 \mathrm{aa})\end{array}$ \\
\hline CT6I6 (AAC68220) & hypoth, $429 \mathrm{aa}$ & 0 & 0 & $2 \mathrm{e}-101$ & $8 e-115$ & $3 e-114$ & $2 \mathrm{e}-09,435 \mathrm{aa}$ & Giardia lamblia $(0.003,1024 a a)$ \\
\hline CT623 (AAC68227) & $\begin{array}{l}76 \mathrm{kDa} \text { Homolog, } \\
446 \mathrm{aa}\end{array}$ & 0 & $2 e-155$ & $5 e-152$ & le-154 & le- 157 & le-28, 470aa & $\begin{array}{l}\text { Mycobacterium tuberculosis }(0.18, \\
550 \mathrm{aa})\end{array}$ \\
\hline CT63I (AAC68235) & hypoth, 84aa & le-32 & $2 e-31$ & le-24 & $3 e-28$ & $8 e-28$ & |e-II, 82aa & No other BLAST hits \\
\hline CT635 (AAC68239) & hypoth, I44aa & $2 e-62$ & $5 e-58$ & $6 e-45$ & le-50 & $2 e-5 I$ & $4 \mathrm{e}-04,146 \mathrm{aa}$ & Gallus gallus $(0.003,1748 \mathrm{aa})$ \\
\hline CT642 (AAC68246) & hypoth, 27 laa & $2 e-134$ & $2 e-116$ & $2 e-74$ & $2 e-79$ & $8 e-81$ & $2 \mathrm{e}-22,300 \mathrm{aa}$ & Rattus norvegicus (1.6, 509aa) \\
\hline CT652.I (AAC68830) & hypoth, 59aa & $5 e-26$ & $3 e-24$ & $7 e-12$ & $3 e-12$ & $7 e-13$ & 3e-05, 75aa & Parachlamydia sp. $(0.12,70 \mathrm{aa})$ \\
\hline CT666 (AAC6826I) & hypoth, $83 a a$ & $5 e-40$ & $9 e-31$ & $3 e-35$ & le-36 & $9 e-37$ & $0.43,92 \mathrm{aa}$ & Sacchromyces cerevisiae $(3.7,604 \mathrm{aa})$ \\
\hline CT667 (AAC68262) & hypoth, 149 aa & $3 e-78$ & le-65 & $3 e-51$ & $9 e-55$ & $4 e-55$ & $8 e-16,154 a a$ & $\begin{array}{l}\text { Legionella pneumophila }(0.005 \text {, } \\
577 \mathrm{aa})\end{array}$ \\
\hline CT670 (AAC68265) & hypoth, I68aa & le-29 & le-27 & $2 e-23$ & $4 e-24$ & $3 e-23$ & $9 e-10,165 a a$ & No other BLAST hits \\
\hline CT734 (AAC68329) & hypoth, 22 I aa & $7 e-106$ & le-95 & $2 e-5 I$ & le-56 & $2 e-57$ & le-08, 240aa & $\begin{array}{l}\text { Caenorhabditis briggsae (I.I, } \\
\text { I072aa) }\end{array}$ \\
\hline CT764 (AAC68359) & hypoth, 268aa & $2 \mathrm{e}-154$ & $4 e-113$ & le-46 & $7 e-59$ & $4 e-59$ & $2 \mathrm{e}-05,256 \mathrm{aa}$ & Tetraodon nigroviridis (1.5, 388aa) \\
\hline CT788 (AAC68383) & $\begin{array}{l}\text { leader }(60) \\
\text { peptide- } \\
\text { periplasmic, } 166 \mathrm{aa}\end{array}$ & le-79 & $3 e-61$ & $9 e-25$ & $4 e-34$ & le-32 & $0.003,158 a a$ & $\begin{array}{l}\text { Caenorhabditis elegans }(0.19, \\
227 \text { Iaa) }\end{array}$ \\
\hline СТ809 (AAC68405) & hypoth, 103aa & le-55 & $\begin{array}{l}\text { 2e-44, } \\
146 a a\end{array}$ & $5 e-17$ & $2 e-23$ & $2 e-21$ & $4 e-05,158 a a$ & Canis familiaris (2.I, I83 Iaa) \\
\hline CT838 (AAC68435) & $\begin{array}{l}\text { YjgP/YjgQ family } \\
\text { protein, 366aa }\end{array}$ & 0 & 0 & e- 126 & e- 130 & $3 e-128$ & $6 e-24,360$ aa & $\begin{array}{l}\text { Prochlorococcus marinus }(0.18 \text {, } \\
592 \mathrm{aa})\end{array}$ \\
\hline CT845 (AAC68442) & hypoth, 92aa & $2 e-46$ & $7 e-33$ & $1 e-19$ & $2 \mathrm{e}-17$ & Ie-17 & $8 \mathrm{e}-10,85 \mathrm{aa}$ & Candida albicans $(2.7,557 \mathrm{aa})$ \\
\hline CT849.I (AAC68455) & hypoth, 62aa & $2 e-28$ & $9 e-24$ & $5 e-10$ & $2 e-09$ & le-08 & le-05, 8 laa & No other BLAST hits \\
\hline СТ865 (AAC68463) & hypoth, 329aa & $2 e-180$ & $8 e-146$ & $7 e-76$ & le-77 & $4 e-78$ & $9 e-23,352 a a$ & $\begin{array}{l}\text { Bacteroides thetaiotaomicron }(0.20 \text {, } \\
808 \mathrm{aa})\end{array}$ \\
\hline
\end{tabular}

The Chlamydiales-specific proteins were identified by systematic BLASTP searches using Chl. trachomatis ORFs as probes, where the only significant BLAST hits obtained were for chlamydiae species (see Methods section). Accession numbers of the query sequences are shown beside the Chl. trachomatis loci (CT number) in the first column. The observed expected $(E)$ values for various chlamydiae homologs as well as the first nonchlamydial hit in the BLAST results are given. $E$ values of 0.0 indicate an extremely high degree of similarity between proteins sequences. The second column describes the function and the size of each query protein (protein sizes are described for other chlamydiae only if they noticeably differ from the query protein). Abbreviations are: C. tra, Chl. trachomatis; C. mur; Chl. muridarum; C. pne, Chlam. pneumoniae; C. cav, Chlam. caviae; C. abo, Chlam. abortus; hypoth, hypothetical protein; Omc; Outer membrane cytochrome; OMP, outer membrane protein; Protochlam,

Protochlamydia; Pred., Predicted; PTMP, Possible transmembrane protein.

species, or where all hits showing significant homology to the query protein (see Methods section) were members of the Chlamydiales. These studies have resulted in the identification of large number of signature proteins, which are uniquely found in chlamydiae species. Some of these proteins are present in all available chlamydial sequences indicating that they are likely specific for the entire Chlamydiales phylum. Other proteins were found to be specific for only the Chlamydiaceae family or the two genera, Chlamydia and the Chlamydophila, which comprise this family. Additionally, large numbers of proteins that are unique to $P$. amoebophila were also identified. Most of the identified chlamydiae-specific proteins or ORFs are annotated as hypothetical, hence their functions remain unknown. The genes for most of these proteins are scattered throughout the Chl. trachomatis and Chlam. caviae genomes, however a number of these hypothetical proteins were also found in clusters. Although, it is not clear whether these genes form operons, the presence of these genes in clusters suggest that they could be involved in related functions [26]. In the description of these proteins that follows, the "CT", "CC" and "PC" part of the descriptors refer to the source of the original query protein sequence from Chl. trachomatis (CT), Chlam. caviae (CCA) and $P$. amoebophila (PC) genomes, respectively.

\section{Chlamydiales-specific proteins}

Proteins were considered Chlamydiales-specific if they were present in all sequenced Chlamydia and Chlamydophila genomes, as well as $P$. amoebophila, but were absent in all other bacteria. A total of 59 Chlamydiales-specific proteins were identified (Table 1). Of these, 49 peptides were annotated hypothetical indicating that these organisms have created new strategies allowing them to pursue a parasitic lifestyle with a minimum gene complement. Upon examination of the positions of various Chlamydiales-specific proteins within the Chl. trachomatis and Chlam. caviae genomes, some of them were found to be 
Table 2: A Listing of the Identified Chlamydiaceae-specific proteins

\begin{tabular}{|c|c|c|c|c|c|c|c|}
\hline Protein Loci & Protein (Name/Size) & C. tra & C. mur & C. pne & C. cav & C. abo & $\begin{array}{l}\text { Next best BLAST hit (E value, } \\
\text { protein length) }\end{array}$ \\
\hline СТ006 (AAC67596) & hypoth, 189aa & $3 e-95$ & $6 e-72$ & $3 e-12$ & $9 e-10$ & $2 \mathrm{e}-09$ & Listeria anguillarum $(0.45,3 \mathrm{I} 4 \mathrm{aa})$ \\
\hline СТ005 (AAC67595) & hypoth, $363 \mathrm{aa}$ & |e-1I7 & $4 e-63$ & $3 e-18,417 a a$ & $8 e-20$ & le-20 & Ashbya gossypii $(0.86,2272 a a)$ \\
\hline CT0।8 (AAC 67608) & hypoth, 157aa & $3 e-89$ & $5 e-53$ & $2 \mathrm{e}-10$ & $8 e-09$ & $3 e-06$ & Acetabularia acetabulum $(3.9,613 \mathrm{aa})$ \\
\hline СТ046 (AAC67637) & $\begin{array}{l}\text { Histone-like protein } \\
\text { HC2, 203aa }\end{array}$ & $2 e-29$ & $2 e-25$ & $2 \mathrm{e}-05,172 \mathrm{aa}$ & $8 \mathrm{e}-08,152 \mathrm{aa}$ & $2 e-08$ & No other BLAST hits \\
\hline CT080 (AAC6767I) & LtuB protein, 97 aa & $3 e-50$ & $4 e-37$ & $3 e-11$ & $2 e-13$ & $9 e-16$ & Clostridium tetani $(0.73,3 \mathrm{I} \mathrm{laa})$ \\
\hline СТ082 (AAC67673) & hypoth, 560aa & 0 & 0 & $7 e-91$ & $8 e-103$ & $2 e-102$ & $\begin{array}{l}\text { Saccharomycecs cerevisiae }(2.0 \\
\text { 1537aa) }\end{array}$ \\
\hline СТ083 (AAC67674) & hypoth, 160aa & $|e-7|$ & le-57 & $7 e-30$ & $4 e-29$ & $9 e-25$ & Pseudomonas putida $(0.17,1162 \mathrm{aa})$ \\
\hline CTI09 (AAC67700) & hypoth, $262 \mathrm{aa}$ & $2 e-149$ & $9 e-133$ & $8 e-66$ & $4 e-70$ & $7 e-70$ & Plasmodium falciparum (I.I, I057aa) \\
\hline CTI 42 (AAC67733) & hypoth, 285 aa & $3 e-155$ & $2 e-109$ & le-39 & $9 e-50$ & $6 e-49$ & Heterobasidion annosum $(5.0,507 \mathrm{aa})$ \\
\hline CTI43 (AAC67734) & hypoth, $280 \mathrm{aa}$ & $3 e-165$ & $3 e-123$ & $2 e-36$ & $9 e-55$ & $4 e-56$ & porcine $(0.26,725 \mathrm{aa})$ \\
\hline CTI44 (AAC67735) & hypoth, $285 \mathrm{aa}$ & $2 e-143$ & $3 e-101$ & $7 e-28$ & $9 e-34$ & $6 e-31$ & Staphylococcus aureus $(0.04 \mathrm{I}, 154 \mathrm{aa})$ \\
\hline CTI 47 (AAC67738) & hypoth, 1449aa & 0 & 0 & $3 e-7 l$ & $4 e-88$ & $4 e-91$ & Homo sapiens (8e-10, 2442aa) \\
\hline CTI78 (AAC67769) & hypoth, $404 a a$ & 0 & 0 & $3 e-114$ & $3 e-120$ & $4 e-122$ & $\begin{array}{l}\text { Thiobacillus denitrificans (2e-15, } \\
830 \mathrm{aa})\end{array}$ \\
\hline CTI95 (AAC67787) & hypoth, 363aa & 0 & $2 e-147$ & $8 e-55$ & $4 e-71$ & le-68 & Escherichia coli (1.5, 346aa) \\
\hline CT232 (AAC67824) & $\operatorname{lncB}, 115 \mathrm{aa}$ & $7 e-45$ & le-29 & $4 \mathrm{e}-11$ & $2 e-08$ & $7 e-10$ & Canis familiaris $(0.59,472 \mathrm{aa})$ \\
\hline CT233 (AAC67825) & IncC, I78aa & $9 e-75$ & $3 e-38$ & $0.52,203 \mathrm{aa}$ & $4 e-04$ & $\begin{array}{l}0.006 \\
184 a \mathrm{a}\end{array}$ & Tetraodon nigroviridis $(0.5,1010 \mathrm{aa})$ \\
\hline CT253 (AAC67846) & hypoth, $215 \mathrm{aa}$ & $5 e-108$ & 2e-99 & $2 e-67$ & $5 e-72$ & $8 e-73$ & $\begin{array}{l}\text { Schizosaccharomyces pombe }(0.12 \text {, } \\
880 \mathrm{aa})\end{array}$ \\
\hline CT263 (AAC67856) & hypoth, 196aa & $7 e-109$ & le-72 & $5 e-23$ & $2 e-31$ & le-29 & Mycobacterium bovis $(2.4,744 \mathrm{aa})$ \\
\hline CT288 (AAC6788I) & hypoth, $563 \mathrm{aa}$ & 0 & $3 e-175$ & $6 e-16$ & $5 e-23$ & le-25 & $\begin{array}{l}\text { Debaryomyces hansenii (4e-04, } \\
2042 \mathrm{aa})\end{array}$ \\
\hline CT289 (AAC67882) & hypoth, $379 \mathrm{aa}$ & $3 e-167$ & $3 e-95$ & $6 e-27$ & $6 e-38$ & $5 e-31$ & $\begin{array}{l}\text { Streptococcus pyogenes }(0.049 \text {, } \\
535 \mathrm{aa})\end{array}$ \\
\hline CT324 (AAC679I7) & hypoth, 303aa & $|e-| 6 \mid$ & $8 e-115$ & le-50 & $6 e-55$ & le-55 & Brucella melitensis $(0.29,263 \mathrm{aa})$ \\
\hline CT330 (AAC67925) & hypoth, $90 \mathrm{aa}$ & $2 e-44$ & le-32 & $3 e-07$ & $3 e-04$ & le-05 & Oryza sativa $(2.7,677 \mathrm{aa})$ \\
\hline CT338 (AAC67933) & hypoth, I53aa & le-86 & $1 \mathrm{e}-66$ & le-23 & $2 e-29$ & $5 e-28$ & Acinetobacter sp. (1.6, 304aa) \\
\hline CT365 (AAC6796I) & hypoth, $575 \mathrm{aa}$ & 0 & $4 e-156$ & $3 e-58$ & $7 e-63$ & $|e-6|$ & No other BLAST hits \\
\hline CT372 (AAC67968) & hypoth, 442aa & 0 & 0 & $|e-1| 4$ & $2 e-116$ & $3 e-119$ & $\begin{array}{l}\text { Bradyrhizobium japonicum }(0.016 \text {, } \\
675 \mathrm{aa})\end{array}$ \\
\hline CT377 (AAC67973) & LtuA, 46aa & $4 e-20$ & $8 e-19$ & $2 e-08$ & $6 e-11$ & $5 e-10$ & No other BLAST hits \\
\hline CT383 (AAC67979) & hypoth, 243 aa & $7 e-140$ & le-88 & $3 e-26$ & $2 e-35$ & $2 e-28$ & Burkholderia fungorum $(2.9,780 \mathrm{aa})$ \\
\hline СT392 (AAC67989) & yprS, 377aa & 0 & $2 e-116$ & le-07 & le-14 & $3 e-07$ & $\begin{array}{l}\text { Saccharomyces cerevisiae }(0.048 \\
\text { 1038aa) }\end{array}$ \\
\hline CT4I2 (AAC68009) & PmpA, 975aa & 0 & 0 & $8 e-14 \mid$ & $3 e-179$ & $4 e-175$ & $\begin{array}{l}\text { many other chlamydiae hits in } \\
\text { between Chloroflexus aurantiacus } \\
\text { (3e-05, 767aa) }\end{array}$ \\
\hline CT4I3 (AAC680I0) & PmpB, I75Iaa & 0 & 0 & 0 & 0 & 0 & $\begin{array}{l}\text { Chloroflexus aurantiacus, 8e-10, } \\
767 \text { aa }\end{array}$ \\
\hline CT42I.I (AAC68030) & hypoth, 53 aa & $7 e-23$ & $3 e-20$ & $4 \mathrm{e}-15$ & $6 e-12$ & |e-14 & $\begin{array}{l}\text { Bradyrhizobium japonicum (3.8, } \\
\text { 803aa) }\end{array}$ \\
\hline CT440 (AAC68039) & hypoth, II2aa & le-58 & $2 e-45$ & $6 e-08$ & le-04 & $4 e-07$ & $\begin{array}{l}\text { Homo sapiens }(0.017,100 \mathrm{aa}) \\
\text { (partial) }\end{array}$ \\
\hline CT442 (AAC6804I) & $15 \mathrm{kDa}$ SRP, I50aa & $7 e-70$ & le-33 & le-04 & $\mid \mathrm{e}-12$ & $3 e-12$ & No other BLAST hits \\
\hline CT444 (AAC68043) & OmcA, 88aa & le-39 & $4 e-31$ & $2 e-12$ & $6 e-15$ & $6 e-15$ & Ovis aries $(0.14,197 a a) * *$ \\
\hline CT466 (AAC68066) & hypoth, 109aa & $5 e-48$ & $7 e-39$ & $2 e-24$ & le-26 & le-27 & $\begin{array}{l}\text { Geobacter metallireducens }(0.55 \text {, } \\
557 \text { aa) }\end{array}$ \\
\hline CT47I (AAC6807I) & hypoth, $200 \mathrm{aa}$ & $5 e-112$ & |e- 103 & le-46 & le-62 & $5 e-63$ & Azoarcus sp. (1.9, 168aa) \\
\hline CT482 (AAC68082) & hypoth, $217 a a$ & $1 \mathrm{e}-115$ & $|e-9|$ & le-49 & $6 e-60$ & $4 e-64$ & Legionella pneumophila $(1.8,438 \mathrm{aa})$ \\
\hline CT483 (AAC68083) & hypoth, 121 aa & $|e-5|$ & le-36 & $6 e-06$ & $2 e-08$ & $4 e-08$ & $\begin{array}{l}\text { Rubrobacter xylanophilus (0.14, } \\
\text { 293aa) }\end{array}$ \\
\hline CT529 (AAC68I3I) & hypoth, 298aa & $|e-| 5 \mid$ & $2 e-91$ & $4 e-36$ & le-38 & $8 e-42$ & Aspergillus nidulans (1.9, 274aa) \\
\hline CT552 (AAC68I54) & hypoth, I35aa & $6 e-72$ & $|e-4|$ & $5 e-04$ & $3 e-06$ & $7 e-07$ & Guillardia theta $(0.19,263 \mathrm{aa})$ \\
\hline CT565 (AAC68I67) & hypoth, $147 \mathrm{aa}$ & $7 e-79$ & $1 \mathrm{e}-69$ & $|e-4|$ & $3 e-46$ & $7 e-48$ & Caenorhabditis elegans $(0.11,3 \mid 7 \mathrm{aa})$ \\
\hline CT566 (AAC68I68) & hypoth, $330 \mathrm{aa}$ & $8 e-175$ & $6 e-|4|$ & $8 e-86$ & $4 e-89$ & le-87 & Vibrio vulnificus $(0.26,506 \mathrm{aa})$ \\
\hline CT567 (AAC68169) & hypoth, I74aa & le-87 & $9 e-61$ & $5 e-24$ & $2 e-17$ & $2 \mathrm{e}-17$ & Takifugu rubripes (4.I, I374aa) \\
\hline CT568 (AAC68I70) & hypoth, I5Iaa & $2 e-7 l$ & $4 e-48$ & $2 e-22$ & $2 e-18$ & $5 e-18$ & Giardia lamblia (I.6, 6739aa) \\
\hline
\end{tabular}


Table 2: A Listing of the Identified Chlamydiaceae-specific proteins (Continued)

\begin{tabular}{|c|c|c|c|c|c|c|c|}
\hline CT577 (AAC68I79) & hypoth, I19aa & Te-60 & $3 e-48$ & $6 e-16$ & $3 e-26$ & $2 e-26$ & Giardia lamblia $(0.050,55 \mathrm{I}$ aa) \\
\hline CT578 (AAC68I80) & hypoth, $487 \mathrm{aa}$ & $8 e-175$ & $3 e-150$ & $4 e-81$ & $2 e-99$ & le-103 & Candida glabrata $(0.023,592 \mathrm{aa})$ \\
\hline CT579 (AAC68I8I) & hypoth, $439 \mathrm{aa}$ & $3 e-14 \mid$ & $8 e-115$ & $2 e-76$ & $4 e-77$ & $|e-8|$ & No other BLAST hits \\
\hline CT589 (AAC68191) & hypoth, $602 \mathrm{aa}$ & 0 & 0 & le-126 & le-145 & $3 e-146$ & Bacillus subtilis $(0.052,605 \mathrm{aa})$ \\
\hline CT618 (AAC68222) & hypoth, $266 a a$ & le-142 & $6 e-87$ & $8 e-10$ & $4 \mathrm{e}-19,306 \mathrm{aa}$ & $5 e-22$ & $\begin{array}{l}\text { Drosophila melanogaster (0.1I, } \\
\text { I868aa) }\end{array}$ \\
\hline CT620 (AAC68224) & hypoth, 838aa & 0 & 0 & 0 & $1 e-180$ & $2 e-177$ & Borrelia burgdorferi $(0.29,735 \mathrm{aa})$ \\
\hline CT646 (AAC68823) & hypoth, $459 \mathrm{aa}$ & 0 & 0 & $3 e-60$ & le-68 & $5 e-66$ & Aspergillus nidulans $(5.9,629 \mathrm{aa})$ \\
\hline CT647 (AAC68824) & hypoth, 192aa & $2 e-98$ & $5 e-65$ & $2 e-18$ & Ie-I5 & $3 e-13$ & Ciona intestinalis (I.8, 407aa) \\
\hline CT65I (AAC68828) & hypoth, $608 \mathrm{aa}$ & 0 & 0 & le-97 & $7 e-97$ & $3 e-95$ & $\begin{array}{l}\text { Bacteroides thetaiotaomicron }(0.15, \\
\text { I003aa) }\end{array}$ \\
\hline CT654 (AAC68249) & hypoth, 162aa & $5 e-81$ & $9 e-75$ & le-27 & le-32 & le-33 & Mesocricetus auratus $(2.5,210 \mathrm{aa})$ \\
\hline CT668 (AAC68263) & hypoth, 223 aa & $|e-1| 4$ & $9 e-93$ & $6 e-69$ & $5 e-78$ & le-76 & Bacillus halodurans $(0.045,324 a a)$ \\
\hline CT67I (AAC68266) & hypoth, 283 aa & $2 e-149$ & $|e-1| 5$ & $2 e-63$ & $2 e-76$ & le-72 & Giberella zeae $(0.053,595 \mathrm{aa})$ \\
\hline CT68I (AAC68276) & MOMP, 393aa & 0 & $7 e-176$ & $2 e-139$ & $3 e-137$ & $2 e-136$ & $\begin{array}{l}\text { No other BLAST hits except } \\
\text { chlamydiae }\end{array}$ \\
\hline CT695 (AAC68290) & hypoth, 398aa & 0 & $7 e-147$ & $6 e-12$ & $2 e-23$ & $2 e-22$ & Ustilago maydis $(0.44,417 \mathrm{aa})$ \\
\hline CT696 (AAC6829I) & hypoth, $403 \mathrm{aa}$ & 0 & $3 e-179$ & $6 e-59$ & $3 e-70$ & $2 e-73$ & Mus musculus (0.031, 708aa) \\
\hline CT7I2 (AAC68307) & hypoth, $390 \mathrm{aa}$ & 0 & 0 & $8 e-101$ & le-129 & le-132 & Mus musculus $(0.086,3159 \mathrm{aa})$ \\
\hline CT7I3 (AAC68308) & PorB, 340aa & 0 & 0 & $5 e-120$ & $2 e-133$ & $5 e-132$ & $\begin{array}{l}\text { No other BLAST hits except } \\
\text { chlamydiae }\end{array}$ \\
\hline CT7I8 (AAC683I3) & hypoth, I74aa & $3 e-93$ & $8 e-81$ & $3 e-44$ & $2 e-46$ & $6 e-47$ & Prochlorococcus marinus $(0.82,250 \mathrm{aa})$ \\
\hline CT744 (AAC68339) & phosphoprotein, $82 \mathrm{Iaa}$ & 0 & 0 & $2 e-138$ & $1 e-153$ & $3 e-160$ & Cytophaga hutchinsonii $(0.38,466 \mathrm{aa})$ \\
\hline CT753 (AAC68348) & hypoth, 74aa & $3 e-34$ & $4 e-27$ & le-13, 76aa & $2 e-13$ & $2 e-13$ & Cycas necrotic stunt virus $(1.3,559)$ \\
\hline CT763 (AAC68358) & hypoth, I39aa & $6 e-72$ & $3 e-52$ & $2 e-28$ & $3 e-23$ & $2 e-22$ & $\begin{array}{l}\text { Drosophila pseudoobscura }(2.6, \\
773 a a)\end{array}$ \\
\hline CT795 (AAC68390) & hypoth, I63aa & le-79 & $7 e-46$ & Ie-13 & $3 e-13$ & $2 \mathrm{e}-14$ & Pan troglodytes $(0.52,924 \mathrm{aa})$ \\
\hline CT8I2 (AAC68408) & OmpD, I53Iaa & 0 & 0 & 0 & 0 & 0 & Rhodopirelulla baltica (2e-04, 703aa) \\
\hline CT846 (AAC68443) & hypoth, $234 \mathrm{aa}$ & le- 123 & le- 108 & $7 e-67$ & $3 e-64$ & le-66 & Streptomyces coelicolor (2.1, 689aa) \\
\hline CT847 (AAC68444) & hypoth, I72aa & $2 e-88$ & $8 e-73$ & le-53 & le-53 & $2 e-52$ & $\begin{array}{l}\text { Saccharomyces cerevisiae }(0.001 \text {, } \\
\text { 1434aa) }\end{array}$ \\
\hline CT848 (AAC68445) & hypoth, I68aa & le-76 & $5 e-67$ & $2 e-55$ & $6 e-54$ & $8 e-54$ & $\begin{array}{l}\text { Drosophila pseudoobscura }(0.34 \text {, } \\
\text { 1000aa) }\end{array}$ \\
\hline CT849 (AAC68446) & hypoth, 159aa & $4 e-74$ & le-64 & $2 e-57$ & le-56 & $4 e-57$ & Gallus gallus $(0.034,1546 \mathrm{aa})$ \\
\hline CT860 (AAC68458) & hypoth, 493aa & 0 & $1 e-132$ & $2 e-56$ & $4 e-73$ & $4 e-77$ & Leishmania major $(0.26,1346 \mathrm{aa})$ \\
\hline CT86I (AAC68459) & hypoth, 506aa & 0 & $7 e-172$ & $6 e-67$ & $9 e-74$ & $5 e-76$ & Vibrio fischeri $(0.008,1023 \mathrm{aa})$ \\
\hline CT863 (AAC6846I) & hypoth, $482 \mathrm{aa}$ & 0 & $2 e-150$ & $7 e-82$ & $2 e-86$ & $7 e-90$ & Mus musculus $(0.006,1043 \mathrm{aa})$ \\
\hline CT869 (AAC68467) & OmpE, 964aa & 0 & 0 & $9 e-108$ & $1 e-119$ & $8 e-112$ & Escherichia coli (9e-05, 1250aa) \\
\hline CT870 (AAC68468) & OmpF, I034aa & 0 & 0 & le-40, 93 |aa & $2 e-4 I$ & $5 e-46$ & $\begin{array}{l}\text { long list of chlamydiae homologs ; } \\
\text { Dictyostelium discoideum (4e-04, } \\
485 \text { aa) }\end{array}$ \\
\hline CT87I (AAC68469) & OmpG, I0I3aa & 0 & 0 & $4 e-127$ & $7 e-180$ & $2 e-175$ & $\begin{array}{l}\text { long list of chlamydiae homologs ; } \\
\text { Desulfotalea psychrophila (8e-07, } \\
\text { 2363aa) }\end{array}$ \\
\hline CT872 (AAC68470) & OmpH, I016aa & 0 & 0 & $\begin{array}{l}\text { 6e-152, } \\
978 \text { aa }\end{array}$ & 0 & 0 & $\begin{array}{l}\text { long list of chlamydiae homologs } \\
\text { Crocosphaera watsonii }(0.28,822 \mathrm{aa})\end{array}$ \\
\hline CT874 (AAC68472) & Ompl, 878aa & 0 & 0 & $2 \mathrm{e}-8 \mathrm{I}, 930 \mathrm{aa}$ & $9 e-73,942 a a$ & $2 e-77$ & $\begin{array}{l}\text { long list of chlamydiae homologs } \\
\text { Nostoc punctiforme }(0.006,185 \text { Iaa })\end{array}$ \\
\hline
\end{tabular}

These proteins are uniquely found in various Chlamydiaceae species but not detected in Protochlamydia or other bacterial groups. Other details as in Table I. **OmcA is an annotated ORF in the P. amoebophila genome, however it could not be detected using Chl. trachomatis as probe via BLASTP and so was not considered a Chlamydiales protein; SRP, sulfur rich protein.

clustered on the chromosomes (those with adjacent CT numbers). A few of these gene clusters are discussed below.

Of the proteins annotated with a predicted function, only two represent outer membrane proteins (CT131 and CT546), which is surprising in light of large expansion of genes encoding chlamydial polymorphic membrane proteins $[15,27]$. One of these proteins CT546 is in a cluster with two other Chlamydiales-specific proteins (CT547 and CT548), whose functions are not known, but they could be involved in related functions [26]. Another important Chlamydiales-specific protein that is involved in the formation of their cell envelope is CT443 (OmcB). OmcB is not actually intercalated into a membrane. However, this protein is $4.4 \%$ cysteine, water-soluble and crosslinked to MOMP and another protein OmcA (CT444) to form the membrane complex $[28,29]$. OmcA and OmcB are two of 
Table 3: Chlamydia-specific proteins

\begin{tabular}{|c|c|c|c|c|}
\hline Protein Loci & Protein Name/Size & C. tra & C. mur & Next Best Hit (E value, protein length) \\
\hline CTII5 (AAC67706) & $\operatorname{lncD},|4|$ aa & $4 e-45$ & $5 e-11,124 a a$ & No other BLAST hits \\
\hline CTII6 (AAC67707) & IncE, I 32aa & $2 e-45$ & $4 \mathrm{e}-14,143 \mathrm{aa}$ & No other BLAST hits \\
\hline CTII7 (AAC67708) & IncF, I04aa & $3 e-29$ & $6 e-25,104 a a$ & No other BLAST hits \\
\hline CTII8 (AAC67709) & IncG, I67aa & $5 e-59$ & $8 \mathrm{e}-11,166 \mathrm{aa}$ & Mesorhizobium loti (8.2, I0 Iaa) \\
\hline CTI35 (AAC67726) & hypoth, 360aa & $4 e-179$ & $4 \mathrm{e}-115,365 \mathrm{aa}$ & Hepatitis $C$ virus $(0.86,4 \mid 4 a a)$ \\
\hline CTI 63 (AAC67754) & hypoth, $548 a a$ & 0 & $8 \mathrm{e}-13,246 \mathrm{aa}$ & Canis familiaris $(1.5,197 \mathrm{Iaa})$ \\
\hline CTI74 (AAC67765) & hypoth, I5Iaa & $9 e-81$ & $4 \mathrm{e}-10,120 \mathrm{aa}$ & Streptococcus pyogenes $(0.066,152 \mathrm{aa})$ \\
\hline CTI92 (AAC67784) & hypoth, 257 aa & |e- 120 & $2 \mathrm{e}-33,23$ Iaa & Caenorhabditis briggsae (1.9, 1572aa) \\
\hline CT226 (AAC678I8) & hypoth, I76aa & $4 e-72$ & $2 \mathrm{e}-12,166 \mathrm{aa}$ & Cryptosporidium parvum $(0.50,1366 \mathrm{aa})$ \\
\hline CT227 (AAC67819) & hypoth, I33aa & $4 e-46$ & $2 \mathrm{e}-04,138 \mathrm{aa}$ & Symbiobacterium thermophilum (8.2, I43aa) \\
\hline CT228 (AAC67820) & hypoth, 196aa & $5 e-76$ & $4 \mathrm{e}-28,210 \mathrm{aa}$ & Campylobacter jejuni $(2.5,176 \mathrm{aa})$ \\
\hline СТ229 (AAC6782I) & hypoth, $215 \mathrm{aa}$ & $2 e-86$ & $4 \mathrm{e}-28,214 \mathrm{aa}$ & Bos taurus $(0.006,1976 \mathrm{aa})$ \\
\hline CT249 (AAC67842) & hypoth, II6aa & $6 e-41$ & $3 e-20,115 a a$ & No other BLAST hits \\
\hline CT300 (AAC67893) & hypoth, II5aa & $2 e-44$ & $2 \mathrm{e}-05,127 \mathrm{aa}$ & Pan troglodytes $(6.3,294 a a)$ \\
\hline CT326.2 (AAC67924) & hypoth, $60 \mathrm{aa}$ & $2 e-28$ & $3 e-04$ & No other BLAST hits \\
\hline CT345 (AAC67940) & hypoth, 12 Iaa & $2 e-52$ & $5 e-24,121$ aa & Haemophilus ducreyi $(4.7,22$ I aa) \\
\hline CT357 (AAC67953) & hypoth, II0aa & $8 e-30$ & $9 e-07,106 a a$ & No other BLAST hits \\
\hline CT358 (AAC67954) & hypoth, I78aa & $2 e-79$ & $8 \mathrm{e}-31,170 \mathrm{aa}$ & Anabaena variabilis $(0.079,185 \mathrm{aa})$ \\
\hline CT360 (AAC67956) & hypoth, 208aa & $2 e-94$ & $2 \mathrm{e}-46,212 \mathrm{aa}$ & Caenorhabditis Elegans $(0.052,728 \mathrm{aa})$ \\
\hline CT694 (AAC68289) & hypoth, $323 \mathrm{aa}$ & $2 e-177$ & $8 e-92,334 a a$ & Psychrophila sp. $(0.56,335 \mathrm{aa})$ \\
\hline
\end{tabular}

These proteins are uniquely found in species belonging to the Chlamydia genus and are absent in the Chlamydophila and Protochlamydia.

the very few chlamydiae-specific proteins that have been functionally characterized $[28,29]$. The OmcA (CT444) protein is $15 \%$ cysteine and so has homology only to proteins with high cysteine content. It has a classic SPII signal sequence and is a proven lipoprotein $[28,29]$. OmcA and OmcB are transcribed together $[28,29]$ and the proteins that are annotated as OmcA and OmcB are present in all genome sequenced chlamydiae [13-16], including $P$. amoebophila [11]. However, in BLASTp searches using either the Chl. trachomatis or Chlam. caviae OmcA (CCA00184) homologs as the query proteins (with or without the low complexity filter), an OmcA homolog was not detected in $P$. amoebophila although a protein PC0617 (accession number YP_007016) has been annotated as its OmcA homolog. Hence, by the criteria used in this study we regard CT444 as a Chlamydiaceae-specific and not a Chlamydiales-specific protein, and we have included it in Table 2. OmcA and OmcB annotation is presently based on the high cysteine content of the predicted protein products, as the cysteine residues are the basis for OmcA and OmcB function in Chlamydiaceae. Because OmcA and OmcB annotation has changed many times in the literature over the last 15 years $[28,29]$, these proteins are best located by BLAST search. It should be mentioned that besides the Chlamydiales a homolog of CT443 with low E value (3e-25) is also found in Rhodopirellula baltica (Table 1). The R. baltica protein (accession number CAD72259) is larger in length (907aa) in comparison to the chlamydiae homolog and the sequence similarity between these two proteins is mainly seen in the C-terminal region. Importantly, the R. baltica homolog of
OmcB contains no cysteine, hence the possible significance of the presence of this homologous protein in $R$. baltica (Planctomycetes) is presently unclear. A close relationship of chlamydiae to the Planctomycetes, which also lack peptidoglycan in their cell wall, has been noted in earlier studies [30,31]. Although such a relationship was not supported in a later study [32], in view of the presence of this commonly shared protein, it would be of interest to reexamine the relationship between these groups based on genomic sequences.

The finding of only a limited number of outer membrane proteins unique to various Chlamydiales suggests that the chlamydiae species most likely favour lineage-specific mechanisms or surface receptors for interacting with their different hosts rather than sharing a homologous system. Cell surface interactions are not limited to the outer membrane proteins. The LysM domain is a widespread protein module, which the available evidence suggests is a general peptidoglycan-binding module in cell surface proteins associated with cell wall degradation [33]. A LysM domain protein (CT474) was found to be common in all members of the Chlamydiales sequenced to date. The presence of this protein is intriguing as chlamydiae are not known to contain detectable levels of peptidoglycan (PG), despite housing genes for almost a complete PG biosynthetic pathway [34-36].

In addition to interacting with their hosts via cell surface molecules, the chlamydiae are also known to utilize a type III secretion system [37]. Genes encoding the basic type III 
Table 4: Listing and Characteristics of Chlamydophila-specific proteins

\begin{tabular}{|c|c|c|c|c|c|}
\hline Protein Loci & Protein Name/Size & C. cav & C. abo & C. pne & Next Best Hit \\
\hline CCA00062 (AAP048I4) & YwbM, 463aa & 0 & $6 e-113,50 \mathrm{laa}$ & |e-|4, 382aa & Aspergillus nidulans $(0.56,182 \mathrm{aa})$ \\
\hline CCA00I77 (AAP04928) & hypoth, 367 aa & 0 & le-I46, 370aa & $7 e-35,366 a a$ & Tetraodon nigroviridis $(2.7,659 \mathrm{aa})$ \\
\hline CCA00I89 (AAP04940) & hypoth, $316 a a$ & 0 & $2 e-111,316 a a$ & $3 e-60,312 a a$ & $\begin{array}{l}\text { Novosphingobium aromaticivorans }(0.010 \text {, } \\
33 \text { I aa) }\end{array}$ \\
\hline CCA00222 (AAP04973) & put. mb. protein, 123aa & le-55 & $6 e-22,113 a a$ & $3 e-05,110 a a$ & $\begin{array}{l}\text { Campellolebias dorsimaculatus, }(0.04 \text {, } \\
348 \mathrm{aa})\end{array}$ \\
\hline CCA00246 (AAP04997) & put. lipoprotein, $3 \mid 3 \mathrm{aa}$ & 0 & $6 e-158,3 \mid 4 a a$ & $3 e-96,317 a a$ & No other BLAST hits \\
\hline CCA0026I (AAP050I2) & put. mb. protein, 1044aa & 0 & $0,1105 \mathrm{aa}$ & $3 e-64,1033 a a$ & Capsicum annuum $(0.18,576 \mathrm{aa})$ \\
\hline CCA00296 (AAP05045) & hypoth, $448 a a$ & 0 & $4 \mathrm{e}-74,442 \mathrm{aa}$ & $2 \mathrm{e}-35,445 \mathrm{aa}$ & Ralstonia eutropha $(1.6,556 \mathrm{aa})$ \\
\hline CCA00299 (AAP05048) & hypoth, $288 a a$ & $5 e-146$ & $4 e-96,288 a a$ & $3 e-45,289 a a$ & Neurospora crassa $(1.4,54$ laa) \\
\hline CCA00352 (AAP05I00) & hypoth, 197aa & $3 e-95$ & $2 \mathrm{e}-60,204 \mathrm{aa}$ & $5 e-12,212$ aa & Cryptophlebia leucotreta $(0.016,395 \mathrm{aa})$ \\
\hline CCA00353 (AAP05I0I) & hypoth, $186 a a$ & $3 e-85$ & $3 e-60,205 a a$ & le-II, I75aa & Mus musculus $(0.12,718 \mathrm{aa})$ \\
\hline CCA00360 (AAP05I08) & put. inner mb. protein, $97 \mathrm{aa}$ & $4 e-47$ & $4 \mathrm{e}-28,104 \mathrm{aa}$ & le-04, $10 \mathrm{laa}$ & Arabidopsis thaliana $(0.58,5 \mathrm{I} 3 \mathrm{aa})$ \\
\hline CCA0036I (AAP05I09) & put. inner mb. protein, II Oaa & $4 e-57$ & $2 e-42,110 a a$ & $0.014,111$ aa & Bacillus licheniformis $(1.3,416 \mathrm{aa})$ \\
\hline CCA00434 (AAP05I80) & put. inner mb. protein, $45 \mathrm{I}$ aa & 0 & $4 \mathrm{e}-125,435 \mathrm{aa}$ & $6 e-34,424 a a$ & $\begin{array}{l}\text { other Chlamydophila hits ; Apis mellifera } \\
(0.93,1500 \mathrm{aa})\end{array}$ \\
\hline CCA00497 (AAP0524I) & hypoth, $47 \mathrm{I}$ aa & 0 & $3 e-173,47 I$ aa & $|e-55,5| 5 a a$ & Trophyrema whipplei $(2.9,735 \mathrm{aa})$ \\
\hline CCA00530 (AAP05273) & hypoth, $424 \mathrm{aa}$ & 0 & le-32, 435aa & $6 e-26,435 a a$ & Fusobacterium nucleatum $(3.2,448 \mathrm{aa})$ \\
\hline CCA00575 (AAP053I7) & put. lipoprotein, 294aa & $3 e-165$ & le-97, 277aa & $3 e-59,284 a a$ & Wolinella. succinogenes $(2.5,329 a a)$ \\
\hline CCA00576 (AAP053I8) & hypoth I70aa & $7 e-88$ & $1 \mathrm{e}-43,155 \mathrm{aa}$ & $2 \mathrm{e}-18,164 \mathrm{aa}$ & Melanoplus sanguinipes $(0.36,254 \mathrm{aa})$ \\
\hline CCA00578 (AAP05320) & put. lipoprotein, $280 \mathrm{aa}$ & le- 160 & $7 e-08,277 a a$ & $2 e-05,284 a a$ & Plasmodium falciparum $(1.3,294 a a)$ \\
\hline CCA0062I (AAP05363) & PTMP, I08aa & $3 e-54$ & $2 e-33,108 a a$ & $4 e-09,16 I$ aa & Agrobacterium tumefaciens $(0.34,279 \mathrm{aa})$ \\
\hline CCA00738 (AAP05479) & lipoprotein, 95aa & $5 e-35$ & $3 e-15,99 a a$ & $0.003,99 \mathrm{aa}$ & Mycobacterium leprae $(8.5,574 \mathrm{aa})$ \\
\hline
\end{tabular}

These proteins are uniquely found in species belonging to Chlamydophila genus but they are absent in various Chlamydia and Protochlamydia species as well as all other groups of bacteria. Abbreviations: put. inner mb., putative inner membrane protein, PTMP, putative transmembrane protein.

secretory apparatus have been identified in all sequenced Chlamydia, Chlamydophila and Protochlamydia genomes [11,13-15]. These surface projections are used to inject chlamydiae-derived proteins into the host cytosol from within the inclusion body [38]. Orthologs or paralogs to effector proteins commonly found in other bacteria utilizing this apparatus have not been identified in chlamydial systems although they are likely to be critical for transducing the signals required to modulate host cell function. A type III secretion chaperone (CT274) was identified in all Chlamydiales members, which may facilitate a number of processes such as adhesion, cell signaling, transport and the perpetuation of infection. Another Chlamydiales-specific protein, CT273, was found in a tight cluster with CT274. The function of CT273 is not known, but it could also play a role in type III secretion [26]. Both of these genes lie in close proximity to CT271, another Chlamydiales-specific hypothetical protein which resides in the chromosome in the opposite orientation of the above mentioned ORFs.

Due to the reduction in metabolic capabilities of the chlamydiae, it is likely that many different permeases would be necessary for acquiring sufficient levels of different substrate molecules $[18,39]$. Members of the YjgP/ YjqE family are predicted integral membrane proteins containing 6 transmembrane regions which are predicted to function as permeases [40]. Although $\mathrm{YjgP} / \mathrm{YjqE}$ proteins are distributed throughout the major domains of life, a novel protein which is indicated to be related to this family, CT838, is uniquely found in various Chlamydiales. The iron-sulfur protein ferredoxin (Fd) is an electron acceptor which participates in the redox-based metabolisms in plastids, mitochondria and bacteria [41]. A novel predicted ferredoxin is uniquely present in various Chlamydiales species (CT312) suggesting that it serves a common evolutionary adapted function in these groups of species.

Another Chlamydiales specific protein, EUO (CT446), encoded by the euo gene (early upstream open reading frame) is found just upstream of the 2 genes encoding lysine-rich proteins $\mathrm{Hc} 1$ and $\mathrm{Hc} 2$ which are highly similar to the eukaryotic H1 histone $[42,43]$. One study has shown that Hc1 binds to DNA, inducing nucleoid compaction observed late in the chlamydial developmental cycle when vegetative reticulate bodies differentiate into the metablocially inert infectious particles known as elementary bodies [42]. The EUO protein, which is expressed early in the chlamydial cycle, has been shown to specifically cleave the $\mathrm{C}$-terminal portion of $\mathrm{Hc1}$, initiating dissociation of DNA-Hc1 complexes and DNA decondensation [42-44]. Little is known about the signals that trigger the different events throughout the chlamydial 
Table 5: Chlamydial Specific Proteins with Gene Losses in Some Species

\begin{tabular}{|c|c|c|c|c|c|}
\hline $\begin{array}{l}\text { Loci and Accession } \\
\text { Numbers }\end{array}$ & $\begin{array}{l}\text { Loci and Accession } \\
\text { Numbers }\end{array}$ & $\begin{array}{l}\text { Loci and Accession } \\
\text { Numbers }\end{array}$ & $\begin{array}{l}\text { Loci and Accession } \\
\text { Numbers }\end{array}$ & $\begin{array}{l}\text { Loci and Accession } \\
\text { Numbers }\end{array}$ & $\begin{array}{l}\text { Loci and Accession } \\
\text { Numbers }\end{array}$ \\
\hline $\begin{array}{l}\text { Chlamydophila and } \\
\text { Protochlamydia } \\
\text { proteins (absent in } \\
\text { Chlamydia) }\end{array}$ & $\begin{array}{l}\text { Chlamydiales specific } \\
\text { proteins missing } C . \\
\text { abortus }\end{array}$ & $\begin{array}{l}\text { Chlamydiaceae } \\
\text { proteins, missing in } C \text {. } \\
\text { trachomatis }\end{array}$ & $\begin{array}{l}\text { Chlamydiaceae } \\
\text { proteins, missing in } C . \\
\text { pneumoniae }\end{array}$ & $\begin{array}{l}\text { Chlamydiaceae } \\
\text { proteins, missing in } C \text {. } \\
\text { caviae }\end{array}$ & $\begin{array}{l}\text { Chlamydiaceae } \\
\text { proteins, missing in } C \\
\text { muridarum }\end{array}$ \\
\hline $\begin{array}{l}\text { CCA00I54 } \\
\text { (AAP04906) }\end{array}$ & CT550 (AAC68I52) & $\begin{array}{l}\text { CCA0023I } \\
\text { (AAP04982) }\end{array}$ & СТ049 (AAC67640) & СТ244 (AAC67837) & $\begin{array}{l}\text { CCA00470 } \\
\text { (AAP052I5) }\end{array}$ \\
\hline $\begin{array}{l}\text { CCA00I68 } \\
\text { (AAP04919) }\end{array}$ & & $\begin{array}{l}\text { CCA00396 } \\
\text { (AAP05I } 42 \text { ) }\end{array}$ & СТ050 (AAC6764I) & СТ277 (AAC67870) & $\begin{array}{l}\text { CCA00259 } \\
\text { (AAP050I0) }\end{array}$ \\
\hline $\begin{array}{l}\text { CCA00I80 } \\
\text { (AAP0493I) }\end{array}$ & & $\begin{array}{l}\text { CCA00425 } \\
\text { (AAP05I7I) }\end{array}$ & СТ05I (AAC67642) & & \\
\hline $\begin{array}{l}\text { CCA00266 } \\
\text { (AAP05017) }\end{array}$ & & $\begin{array}{l}\text { CCA00538 } \\
\text { (AAP0528I) }\end{array}$ & CT2I4 (AAC67806) & & \\
\hline $\begin{array}{l}\text { CCA00333 } \\
\text { (AAP0508I) }\end{array}$ & & $\begin{array}{l}\text { CCA00827 } \\
\text { (AAP05568) }\end{array}$ & СT867 (AAC68465) & & \\
\hline $\begin{array}{l}\text { CCA00495 } \\
\text { (AAP05239) }\end{array}$ & & $\begin{array}{l}\text { CCA00910 } \\
\text { (AAP05649) }\end{array}$ & СT868 (AAC68466) & & \\
\hline \multicolumn{6}{|l|}{$\begin{array}{l}\text { CCA00619 } \\
\text { (AAP0536I) }\end{array}$} \\
\hline \multicolumn{6}{|l|}{$\begin{array}{l}\text { CCA00733 } \\
\text { (AAP05474) }\end{array}$} \\
\hline \multicolumn{6}{|l|}{$\begin{array}{l}\text { CCA00743 } \\
\text { (AAP05484) }\end{array}$} \\
\hline \multicolumn{6}{|l|}{$\begin{array}{l}\text { CCA00855 } \\
\text { (AAP05596) }\end{array}$} \\
\hline $\begin{array}{l}\text { Loci and Accession } \\
\text { Numbers }\end{array}$ & $\begin{array}{l}\text { Loci and Accession } \\
\text { Numbers }\end{array}$ & $\begin{array}{l}\text { Loci and Accession } \\
\text { Numbers }\end{array}$ & $\begin{array}{l}\text { Loci and Accession } \\
\text { Number }\end{array}$ & & \\
\hline $\begin{array}{l}\text { Chlamydiaceae } \\
\text { proteins, missing } C \text {. } \\
\text { abortus }\end{array}$ & $\begin{array}{l}\text { Chlamydophila } \\
\text { proteins, missing } C \text {. } \\
\text { pneumoniae }\end{array}$ & $\begin{array}{l}\text { Chlamydia proteins } \\
\text { also in C. pneumoniae }\end{array}$ & $\begin{array}{l}\text { Chlamydiales, } \\
\text { Rickettsiales and } \\
\text { plastids }\end{array}$ & & \\
\hline CT444.I (AAC68048) & $\begin{array}{l}\text { CCA00075 } \\
\text { (AAP04827) }\end{array}$ & CT785 (AAC68380) & $\begin{array}{l}\text { СT065 (O84068) } \\
\text { CT495 (O84502) }\end{array}$ & & \\
\hline CT702 (AAC68297) & & & $\begin{array}{l}\text { CT065 (O84068) } \\
\text { CT495 (O84502) }\end{array}$ & & \\
\hline
\end{tabular}

These chlamydiae-specific proteins are either missing in some species from particular groups or show unexpected presence in some other groups. The $E$ values for these proteins are not listed.

life cycle. However, the unique presence of the EUO protein (CT446) in various Chlamydiales species suggests a common mechanism for chromatin remodeling.

The Chl. trachomatis locus CT583 encodes Gp6D, a genomic paralog ( $31 \%$ similarity) of a plasmid-born virulence factor pGp6D [45]. Three of the four sequenced Chlamydiaceae species (except Chlam. abortus) [2] have been found to contain extrachromosomal DNA elements (cryptic plasmids) believed to encode genes which might play a role in pathogenicity and/or modulating virulence [46]. P. amoebophila does not contain an extrachromosomal plasmid. The chlamydial plasmids encode 8 ORFs of significance ( $>100$ amino acids), and although 5 have been characterized, the function of pGp6D is unknown
[45]. While the plasmid-borne pGp6D is only 102aa long, the genomic Gp6D homolog found in all Chlamydiales is more than twice that size (263aa). The high degree of similarity among plasmids from both Chlamydia and Chlamydophila species suggests that an ancestral plasmid was acquired by the chlamydial lineage, perhaps before divergence of the two Chlamydiaceae genera. That plasmid-less chlamydiae are rare suggests that plasmid loss is selected against - that the plasmids do have a function specific to this family, which is apparently absent in chlamydiae-like organisms. All of the proteins in this category, which are uniquely present in various Chlamydiales, have likely evolved in the last common ancestor of all chlamydiae and were subsequently passed on to various descendent species through vertical descent. 
Table 6: Stage-specific Expression of some of Chlamydiae-specific Proteins

\begin{tabular}{|c|c|c|c|c|}
\hline Stage of Expression & $\begin{array}{l}\text { Chlamydiales-specific } \\
\text { Proteins }\end{array}$ & $\begin{array}{l}\text { Chlamydiaceae-specific } \\
\text { Proteins }\end{array}$ & Chlamydia-specific Proteins & Lost or Transferred Genes \\
\hline I-Early (6-24 hpi) & & СТ233 & & \\
\hline \multirow[t]{6}{*}{ II-Midlate (I2-24 hpi) } & $\begin{array}{l}\text { CT053 } \\
\text { CT635 }\end{array}$ & $\begin{array}{l}\text { CT289 } \\
\text { CT67I }\end{array}$ & CT360 & CT550 \\
\hline & $\begin{array}{l}\text { CT066 } \\
\text { CT666 }\end{array}$ & $\begin{array}{l}\text { CT372 } \\
\text { CT870 }\end{array}$ & & \\
\hline & $\begin{array}{l}\text { CT273 } \\
\text { CT667 }\end{array}$ & $\begin{array}{l}\text { CT377 } \\
\text { CT87I }\end{array}$ & & \\
\hline & $\begin{array}{l}\text { CT504 } \\
\text { CT670 }\end{array}$ & $\begin{array}{l}\text { CT413 } \\
\text { CT } 872\end{array}$ & & \\
\hline & $\begin{array}{l}\text { CT590 } \\
\text { CT734 }\end{array}$ & $\begin{array}{l}\text { CT618 } \\
\text { CT874 }\end{array}$ & & \\
\hline & & CT668 & & \\
\hline \multirow[t]{4}{*}{ III-Midlate (18-24 hpi) } & & CTI42 & & СТ049 \\
\hline & & CTI43 & & СТ05I \\
\hline & & CT68I & & \\
\hline & & CT7I3 & & \\
\hline \multirow[t]{11}{*}{ IV-Late (24-36 hpi) } & СТ016 & $\begin{array}{l}\text { CT005 } \\
\text { CT552 }\end{array}$ & СТ249 & СТ050 \\
\hline & СТ0I7 & $\begin{array}{l}\text { CT046 } \\
\text { CT565 }\end{array}$ & & CT2I4 \\
\hline & CTI8I & $\begin{array}{l}\text { СT080 } \\
\text { CT578 }\end{array}$ & CT694 & CT702 \\
\hline & CT443 & $\begin{array}{l}\text { СT082 } \\
\text { СТ579 }\end{array}$ & & \\
\hline & СТ546 & $\begin{array}{l}\text { СТ083 } \\
\text { СТ620 }\end{array}$ & & СТ868 \\
\hline & & $\begin{array}{l}\text { CTI47 } \\
\text { CT695 }\end{array}$ & & \\
\hline & & $\begin{array}{l}\text { CT288 } \\
\text { CT712 }\end{array}$ & & \\
\hline & & $\begin{array}{l}\text { CT365 } \\
\text { CT848 }\end{array}$ & & \\
\hline & & $\begin{array}{l}\text { CT392 } \\
\text { CT869 }\end{array}$ & & \\
\hline & & CT442 & & \\
\hline & & CT444 & & \\
\hline
\end{tabular}

The temporal expression patterns of these proteins is based upon the microarray analysis of Nicholson et al [63]. According to the microarray profiles, significant differences were seen in the expression pattern of genes for these proteins at 4 different time points (6-24 hours post infection, 12-24 h.p.i., 18-24 h.p.i., and 24-36 h.p.i.) which correspond to different phases of the chlamydial developmental cycle where key phenotypic changes take place. It is of interest that the majority of the temporally regulated Chlamydiales and Chlamydiaceae-specific genes are expressed between 12-24 h.p.i. and 24-36 h.p.i. Such coordinate regulation suggests they play essential roles during these phases of the chlamydial cell cycle. Other chlamydiae-specific proteins which are not listed in this Table were not found to show significant differences in their temporal expression in the study by Nicholson et al. [63]. Abbreviation; h.p.i., hours post infection.

\section{Chlamydiaceae-specific proteins}

The proteins in this grouping corresponded to those which were found strictly in species belonging to members of the Chlamydia and Chlamydophila genera, but whose homologs were not detected in P. amoebophila. Interestingly, among this category of proteins, 12 distinct gene clusters were located (described below). Of the 79 Chlamydiaceae-specific proteins identified in this work (Table 2), 60 were hypothetical. Those with predicted function are discussed below.

Chlamydiae possess an intracellular developmental cycle defined by the orderly interconversion of infectious, met- abolically inactive elementary bodies (EBs) and noninfectious, dividing reticulate bodies (RBs) [1]. Only a few stage-specific genes are known, including the two latestage genes encoding histone-like proteins. While chlamydial Hc1 (histone H1-like protein) is highly conserved (CT446), Hc2 (a second H1-like protein) is less conserved and variable in size (CT046) [42]. While both proteins are thought to participate in DNA compaction, Hc1 is found only in members of the Chlamydiales while Hc2 is found uniquely in the Chlamydiaceae, to the exclusion of Protochlamydia. Indeed, there are no other homologs of this protein outside of the Chlamydiaceae found in BLAST searches using Chl. trachomatis as the probe. LtuA and LtuB (CT377 
Table 7: Sequence Divergence of Some (A) Chlamydiales-specific vs (B) Broadly-Distributed Proteins

\begin{tabular}{|c|c|c|c|c|c|c|}
\hline $\mathbf{A}$ & & & & & & \\
\hline $\begin{array}{l}\text { Protein Loci/ } \\
\text { Identity }\end{array}$ & C. tra & C. mur & C. pneu & C. cav & C. abo & Protochlam \\
\hline СТ007 & $316 / 316(100 \%)$ & $273 / 316(86 \%)$ & |84/3| 6 (58\%) & $185 / 3 \mid 6(58 \%)$ & |83/3| 6 (57\%) & $48 / 316(23 \%)$ \\
\hline СТ016 & $242 / 242(100 \%)$ & $205 / 242(84 \%)$ & $146 / 246$ (59\%) & $153 / 245$ (62\%) & I 48/245 (60\%) & $83 / 246(33 \%)$ \\
\hline СТОI7 & $433 / 433(100 \%)$ & $358 / 440$ (81\%) & $224 / 401$ (55\%) & $24 I / 432(55 \%)$ & $248 / 432$ (57\%) & $123 / 4 \mid 5$ (29\%) \\
\hline СТ02I & $247 / 247$ (100\%) & $184 / 247$ (74\%) & $102 / 244(41 \%)$ & $115 / 244$ (47\%) & $108 / 245$ (44\%) & $73 / 254(28 \%)$ \\
\hline СТ0зІ & $100 / 100(100 \%)$ & $84 / 100(84 \%)$ & $65 / 100(65 \%)$ & $63 / 100(63 \%)$ & $63 / 100(63 \%)$ & $36 / 95(37 \%)$ \\
\hline СТ038 & $116 / 116(100 \%)$ & $95 / 114(83 \%)$ & $55 / 112$ (49\%) & $52 / 98(53 \%)$ & $49 / 98(50 \%)$ & $34 / 94(36 \%)$ \\
\hline Average & $100 \%$ & $81.5 \%$ & $55 \%$ & $56 \%$ & $55 \%$ & $31 \%$ \\
\hline \multicolumn{7}{|l|}{ B } \\
\hline $\begin{array}{l}\text { Protein Loci/ } \\
\text { Identity }\end{array}$ & C. tra & C. mur & C. pneu & C. cav & C. abo & Protochlam \\
\hline CT008 Ribo. HII & $300 / 300(100 \%)$ & $257 / 301$ (85\%) & $186 / 30 \mid(61 \%)$ & $185 / 300(61 \%)$ & $185 / 300(61 \%)$ & $|39 / 30|(45 \%)$ \\
\hline CT009 HthTR & $152 / 152(100 \%)$ & $|33 /| 5 \mid(87 \%)$ & $105 / 143(69 \%)$ & $101 / 143(66 \%)$ & $105 / 143(69 \%)$ & $47 / 162(28 \%)$ \\
\hline СТ0I3 Cyt. Ox. I & $446 / 446(100 \%)$ & $406 / 445$ (91\%) & $317 / 448$ (70\%) & $325 / 446(72 \%)$ & $328 / 446$ (73\%) & $195 / 465(41 \%)$ \\
\hline CT0I5 PhoH & $434 / 434(100 \%)$ & $394 / 434(90 \%)$ & $314 / 424(72 \%)$ & $339 / 430(78 \%)$ & $338 / 430(77 \%)$ & $218 / 433(49 \%)$ \\
\hline CTOI9 IleRS & $1036 / 1036(100 \%)$ & $923 / 1036$ (89\%) & $7 / 5 / 1043(68 \%)$ & $729 / 1043(69 \%)$ & $729 / 1043$ (69\%) & $575 / 1038(55 \%)$ \\
\hline CT022 Ribo. L3I & $108 / 108(100 \%)$ & $103 / 108(95 \%)$ & $90 / 109(81 \%)$ & $87 / 208(80 \%)$ & $86 / 108$ (79\%) & $67 / 117(57 \%)$ \\
\hline СТ034 YtfF & $34 I / 34 I(100 \%)$ & $279 / 341$ (8I\%) & $183 / 338(53 \%)$ & $203 / 338(59 \%)$ & $203 / 339(59 \%)$ & $94 / 281(27 \%)$ \\
\hline Average & $100 \%$ & $88 \%$ & $67 \%$ & $69 \%$ & $69 \%$ & $43 \%$ \\
\hline
\end{tabular}

The pair-wise amino acid sequence identity was determined for various chlamydial species for six $C$. trachomatis proteins that are specific for Chlamydiales (A) and seven other proteins that are broadly distributed in bacteria (B). The numbers in these Tables indicate the length over which the two sequences match each other as well as the \% amino acid identity between the two sequences.

The abbreviations in protein names in part (B) are as follows: Ribo. HII, Ribonuclease HII; HthTR, Helix-turn-helix transcriptional regulator; Cyt. Ox. I, Cytochrome oxidase subunit I; PhoH, PhoH-ATPase; IleRS, Isoleucyl tRNA synthetase; Ribo. L3I, Ribosomal L3I protein; YtfF, YytF-cationic amino acid transporter.

and CT080 respectively) are two other proteins, which are uniquely shared by members of the Chlamydiaceae family. Both of these proteins are not expressed until the RBs begin to reorganize to EBs. These molecules do not bear strong homology to any other known protein and their functions are not known. The ltuB gene exhibits unusual stability properties in that the $5^{\prime}$ end appears to break down, while the 3 ' end accumulates as a stable fragment of about 240 bases [47]. It has been hypothesized that the shorter ltuB RNA functions in someway in the late stage of the chlamydial developmental cycle [47]. These unique Chlamydiaceae specific proteins are likely playing distinctive stage-specific roles in the developmental cycles of the Chlamydia and Chlamydophila genera. The ltuB gene is found in close proximity to a cluster containing two other hypothetical Chlamydiaceae-specific proteins (CT082 and CT083).

A vast array of Chlamydiaceae-specific membrane proteins have been identified in our study, including Major outer membrane protein (MOMP or OmpA, CT681), polymorphic membrane protein PmpA (CT412) and PmpB (CT413) which lie in a cluster, the putative outer membrane proteins OmpD (CT812), OmpE, OmpF, OmpG,
OmpH (CT869-CT872, which are clustered together on the C. trachomatis chromosome) and OmpI (CT874). Several of these predicted outer membrane proteins have recently been shown to be translated and localized to the surface of the chlamydial outer membrane $[27,48]$. Outer membrane proteins of microbial pathogens serve essential roles in engaging the host environment and can be important immunotherapeutic targets [49]. Besides the above outer membrane proteins, several other members of the outer membrane complex were uniquely present in all Chlamydiaceae species. Some of these e.g., porinb(CT713) or SRP (previously annotated as CrpA) (CT442) [50], have been described as being immunogenic. PorB (CT713) is the target of neutralizing antibody responses in vitro and it lies in a cluster with another Chlamydiaceaespecific protein (CT712) of unknown function [51]. OmcA (CT444) is a well characterized chlamydial envelope-related protein (discussed in the previous section) that is found to be Chlamydiaceae-specific in our work. None of these proteins could be detected in the Protochlamydia by BLASTp searches using Chl. trachomatis proteins. Unlike the Pmps and Omps, chlamydial Inc proteins are localized to the chlamydial inclusion membrane. Different Inc proteins share minimal primary 
Table 8: Summary chart of the total unique proteins found for different chlamydiae lineage

\begin{tabular}{ll}
\hline Lineages & Number of unique ORFs (proteins) \\
\hline Chlamydiales (C. trachomatis, C. pneumoniae, C. caviae, C. muridarum, C. abortus, P. amoebophila) & $\mathbf{5 9}$ \\
Chlamydiaceae (C. trachomatis, C. pneumoniae, C. caviae, C. muridarum, C. abortus) & $\mathbf{7 9}$ \\
Chlamydophila (C. pneumoniae, C. caviae, C. abortus) & $\mathbf{2 0}$ \\
Chlamydia (C. trachomatis, C. muridarum) & $\mathbf{2 0}$ \\
P. amoebophila & $\mathbf{4 4 5}$ \\
\hline
\end{tabular}

sequence identity with each other or with other proteins in the databases making the assignment of specific function difficult. Studies of individual Incs have shown that these peptides protrude from the surface of the inclusion and may mimic or bind to host cell proteins that selectively manicure the surface of the inclusion to avoid fusion with phagosomes or the host cell exocytic pathway $[38,52,53]$. Two Inc proteins, IncB (CT232) and IncC (CT233), were found to be unique to various Chlamydiaceae species. IncC is secreted by the type III secretion system and is expressed early during the initial stages of infection, and the gene for this protein lies adjacent to the $i n c B$ loci in a cluster $[37,54]$.

Another Chlamydiaceae specific protein, YprS (CT392), contains cysteine-rich complement-type repeats which are implicated in ligand-binding. Based on these repeat sequences, this protein bears some similarity to the insect vitellogenin and yolk protein receptors (VgR/YPR) family of proteins [55]. Many other Chlamydiaceae specific proteins of unknown functions are present in a number of different clusters including CT142-CT144, CT288/CT289, CT565-CT568, CT577-СT579, СT646/СT647, СT695/ CT696 and CT846-СT849.

\section{Chlamydia- and Chlamydophila- specific proteins}

The Chlamydia and Chlamydophila constitute two of the genera within the Chlamydiaceae family $[1,2]$. Thus, it is likely that unique proteins will be found exclusively in the species belonging to these two groups of bacteria. The genomes of two Chlamydia (Chl. trachomatis and Chl. muridarum) and three Chlamydophila species (viz. Chlam. pneumoniae, Chlam. caviae and Chlam. abortus) have been sequenced. In our work, we have identified twenty unique proteins for each of these two genera. A brief description of these results is presented below.

Of the twenty Chlamydia-specific ORFs identified in this work (Table 3), 16 were hypothetical. Those proteins of predicted function were Incs, specifically $I n c D$, IncE, IncF and IncG (CT115-CT118). These 4 ORFs are transcribed from a single operon in Chlamydia species and when expressed, are not uniformly distributed [56]. Instead, these peptides appear to be concentrated at discrete sites in the inclusion membrane, primarily at sites of membrane-RB contact which can be visualized by both immunofluorescence and electron microscopy [56]. Unlike IncD-G localization, chlamydial MOMP appears to be depleted at the point of contact of RBs with the inclusion membrane but is found throughout the rest of the chlamydial outer membrane [56]. The asymmetric distribution of these proteins suggests that RBs exhibit polarity. The presence of such diversity of chlamydial polypeptides in the inclusion membrane lends support to the concept that chlamydiae actively control the interactions of the inclusion with the host cell to maintain a highly specialized environment favourable to chlamydial replication, in a lineage-specific manner. The other Chlamydia-specific proteins are of unknown function and some of these are arranged in 3 additional clusters, consisting of loci CT134/CT135, CT226-CT229 and CT357/ CT358.

Of the 20 Chlamydophila-specific proteins identified in this work (Table 4), 9 are hypothetical while 11 have been minimally characterized previously. Among this group, four putative lipoproteins were identified, whose functions are not yet understood (CCA00246, CCA00575, CCA00578, CCA00738). Additionally 6 proteins have been described as putative membrane proteins in Chlam. abortus (CCA00222, CCA00261, CCA00621, CCA00360, CCA00361 and CCA00434), of which the last three are thought to be localized to the inner membrane [16]. Loci CC00360 and CC00361 are part of a cluster, which is the only cluster found among Chlamydophila-specific ORFs. This group also contained a serine-rich protein of unknown function, annotated as YwbM (CCA00062), which is absent from other chlamydiae as well as all other organisms.

\section{Protochlamydia-specific proteins}

Protochlamydia amoebophila provides the only completed genome of a Chlamydiales species that belongs to a family other than the Chlamydiaeceae. The comparative genomics studies by Horn et al. [11] determined which of the Protochlamydia proteins were not present in other sequenced chlamydiae genomes. Although the list compiled by these authors contained over $1000 \mathrm{ORFs}$, which were present in 


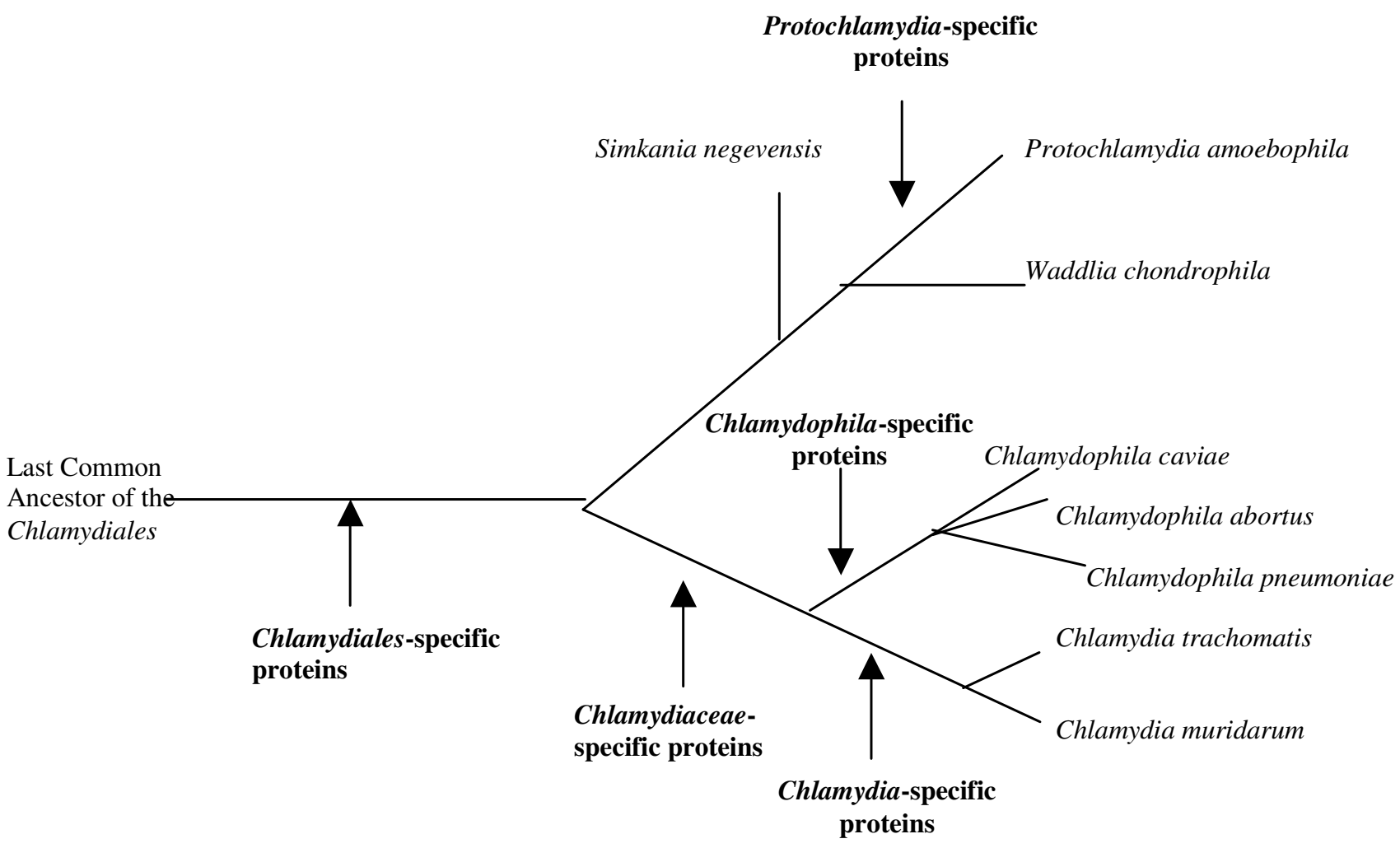

\section{Figure I}

The branching pattern of the chlamydiae species based upon the distribution pattern of different chlamydiae specific proteins. The evolutionary stages where different proteins are indicated to have evolved are marked. The observed relationship is same as that seen in the phylogenetic trees based on I6S rRNA and protein sequences [I,2,25].

Protochlamydia but were absent in other Chlamydiales, their study did not examine which of these proteins were also present in other bacterial phyla. We have undertaken this analysis in order to determine Protochlamydia-specific proteins. A total of 445 Protochlamydial ORFs were identified, and all were of unknown function. The listing of these proteins is provided in the Additional file 1. Most of these peptides were large in size (>300aa). Fifty-five gene clusters were found. These clusters were located at loci PC0055/56, PC0062-64, PC0074-76, PC0080/81, PC0117/18, PC0129/30, PC0293/94, PC0296/97, PC0302-04, PC0408-11， PC0463/64，PC0529/30, PC0535/36, PC0576-80, PC0611/12, PC0698/99, PC0726/27, PC0773/74, PC0812-14, PC0829/30, PC0833/34, PC0836-43, PC0857/58, PC0869/70, PC0885/86，PC0910/11，PC0967/68，PC0982/83, PC1051/52, PC1150-55, PC1204-08, PC1223/24, PC1233/34, PC1283/84, PC1294/95, PC1380/81, PC1387/88， PC1414/15， PC1417/18， PC1517/18, PC1531/32， PC1581-83， PC1621/22， PC1642/43, PC1685-87, PC1692-94, PC1741/42, PC1773-75, PC1789/90, PC1795/96, PC1826/27, PC1870/71, PC1891-94, PC1902-04, and PC1959-61.

\section{Cases of putative gene loss or transfer}

The impact of gene acquisition and loss on bacterial genome evolution is currently a central question in microbiology which remains unresolved. It was therefore of interest to identify cases in which a gene appears to have been lost or possibly transferred from chlamydial genomes. Such cases were detected when all other species of a particular chlamydial group (e.g. Chlamydiales, Chlamydiaceae etc) contained a specific protein, with the exception of one or only a few species. In all, 33 such cases were identified among the different chlamydial groups (Table 5). Interestingly, 10 proteins which were found in the Chlamydophila and Protochlamydia were absent in the two available Chlamydia species (CCA00154, CCA00168, CCA00180, CCA00266, CCA00333, CCA00495, CCA00619, CCA00733, CCA00743, CCA00855). These genes may represent incidences of gene loss in the Chlamydia, or possible gene transfer between the Chlamydophila and Protochlamydia. Some phylogenies based on rRNA support the early separation of Chlamydia $[57,58]$. However, indel analysis and some protein phylogenies indicate that the Chlamydophila are ancestral to the Chlamydia [25]. Among the results, 6 proteins were found in all 


\section{A) Chlamydiales-specific protein CT429}

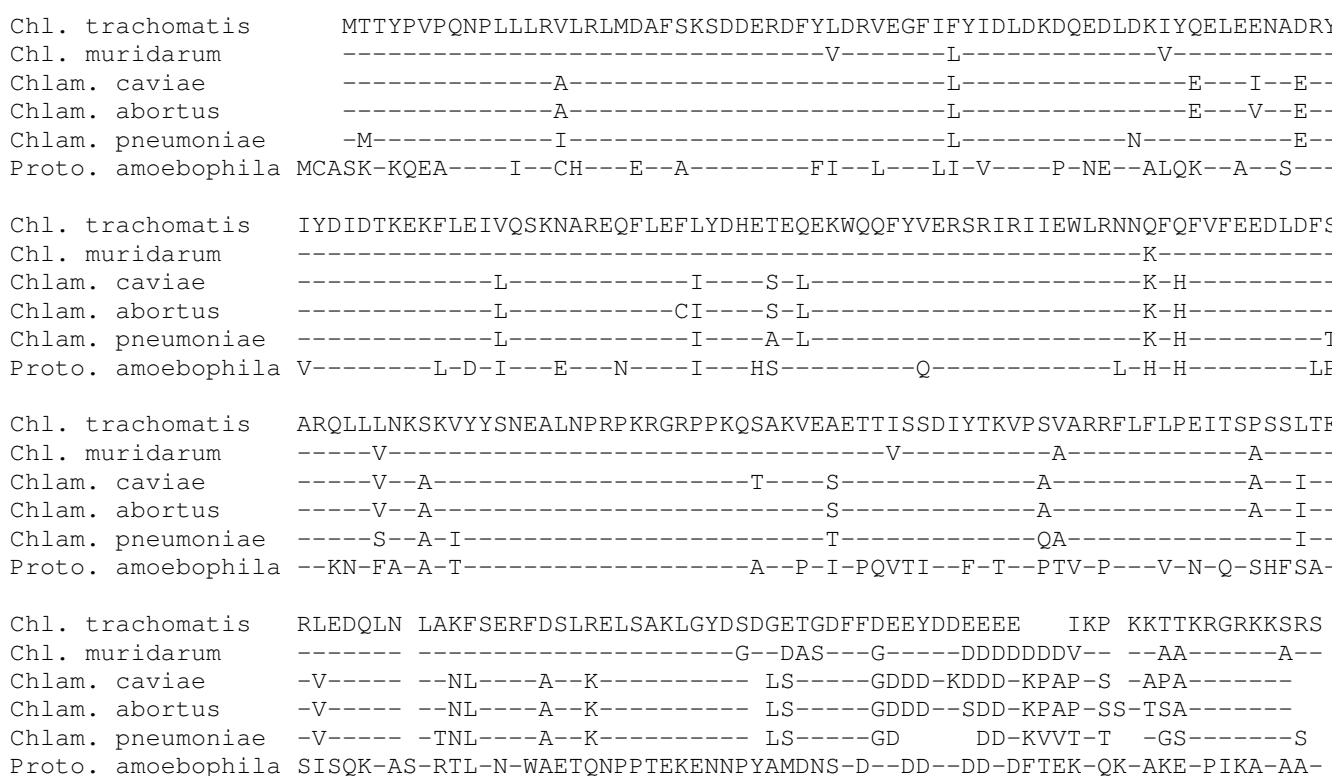

Proto. amoebophila SISQK-AS-RTL-N-WAETQNPPTEKENNPYAMDNS-D--DD--DD-DFTEK-OK-AKE-PIKA-AA-

\section{B) Chlamydiaceae-specific protein CT712}

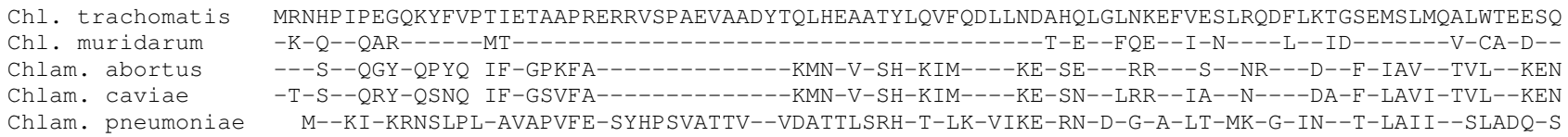

Chl. trachomatis REARKRERKELQQQLESKVLGPQALTTAEELHPVDDSIVNKMPFQSAFAYILLDKYIPAQEEALYALARELSFSGYAQTLFSPVLELVKSFN Chl. muridarum Chlam. abortus Chlam. caviae Chlam. pneumoniae

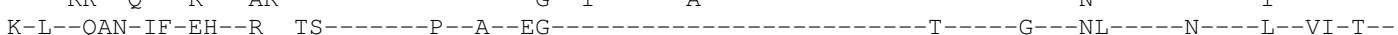
$\mathrm{K}-\mathrm{L}--\mathrm{EAN}-\mathrm{VF}-\mathrm{EH}-\mathrm{DR} \quad \mathrm{IS}-------\mathrm{P}--\mathrm{A}--\mathrm{K}--------------------------\mathrm{T}-----\mathrm{G}---\mathrm{NL}-----\mathrm{N}----\mathrm{L}--\mathrm{TI}----$ $--\mathrm{S}--\mathrm{K}-\mathrm{E}-\mathrm{IFH}-\mathrm{H}-\mathrm{GK} \quad \mathrm{AA}---\mathrm{A}-\mathrm{ATSGVQ}-\mathrm{TA}-\mathrm{PVAD}---\mathrm{L}------\mathrm{V}----------------\mathrm{G}---\mathrm{NL}-----\mathrm{N}----\mathrm{L}-\mathrm{DMI}----$
Chl. trachomatis Chl. muridarum Chlam. abortus Chlam. caviae Chlam. pneumoniae
NAP IVYNLGSYIGQTAGTANF KYGYQMVLDRYETETGQLRKD IKNAENAKQQLAQIYIQTLDVCISQMQELSTGLRGLSF IPGRDEYSPAYE $--------------\mathrm{N}-----\mathrm{R}------\mathrm{M}----\mathrm{M}-\mathrm{NS}-----\mathrm{M}-------\mathrm{L}-\mathrm{F}--\mathrm{V}------\mathrm{A}-\mathrm{LT}---\mathrm{A}--\mathrm{A}-----\mathrm{A}-------\mathrm{F}-----$ $\mathrm{S}---\mathrm{I}-------\mathrm{S}--\mathrm{SD}----------\mathrm{IV}----\mathrm{E}-\mathrm{CLH}-\mathrm{KN}---\mathrm{S}----\mathrm{QLL}-\mathrm{K}---\mathrm{DSE}-\mathrm{VIM}-\mathrm{K}--\mathrm{KN}-\mathrm{MLN}-\mathrm{SS}-\mathrm{I}----\mathrm{NS}--\mathrm{E}-\mathrm{S}-\mathrm{K}$ S---N-------S--S-----A---E-I-S--NN-VS-C-L--ASTVK--AA--NM-TKS---IHT-LTDVM-N-AS IT-V--LNK-D-S-R

\section{Figure 2}

Multiple sequence alignments of a representative Chlamydiales-specific protein CT429 (A), and a Chlamydiaceae-specific protein CT7 2 (B). Both of these proteins are of unknown function and they are uniquely found in the indicated groups of species. The sequence alignments for all available homologs for these proteins are shown. Dashes (-) in the alignments indicate identity with the amino acid on the top line (i.e. Chl. trachomatis sequence). Both these proteins contain many highly conserved regions suitable for PCR primer design that can be used for diagnostic purposes.

Chlamydiaceae species with the exception of Chl. trachomatis (CCA00231, CCA00396, CCA00425, CCA00538, CCA00827, CCA00910). Furthermore, 6 different proteins were found in all Chlamydiaceae species except for Chlam. pneumoniae (CT049, СT050, CT051, CT214, CT867, CT868). Also, 2 proteins were missing from Chlam. caviae which were found in all other available chlamydial species (CT244 and CT277), while 2 different proteins were absent in Chl. muridarum which were present in other Chlamydiaceae genomes (CCA00470, CCA00259). One protein which was unique to all Chlamydiales (CT550) and two proteins which were found in various Chlamydiaceae (CT444.1 and CT702) were also not found in the Chlam. abortus genome. One protein was 
found which was uniquely shared by all Chlamydia species and Chlam. pneumoniae, to the exclusion of all other Chlamydophila which may represent a lateral gene transfer (CCA00075). A single protein was absent in Chlam. pneumoniae which was present in all other Chlamydophila genomes (Chlam. caviae and Chlam. abortus) (CT785). Since Chl. trachomatis and Chlam. pneumoniae were used as probes, it is possible that other genes may have been lost from these genomes which were not identified during the searches. When the functions of these proteins are elucidated, these patterns of putative gene loss will likely shed light on their importance in regards to the differences in chlamydial biology, as well as why such gene losses may have occurred. Another well-studied example of a Chlamydiales protein that is also present in various Rickettsiales as well as various plants and algal plastids, consist of the nonmitochondrial ADP-ATP translocases (CT065 and CT495). Phylogenetic studies indicate that these genes have been transferred from a Chlamydiales ancestor to the other groups where these proteins are found $[59,60]$.

\section{Temporal expression of Chlamydiae-specific genes}

The developmental cycle of chlamydiae is regulated at the transcriptional level, although this regulation is not well understood [61]. Determining the stage-specificity of different genes is important for understanding the development and function of different chlamydial species. In vivo expression studies [62], in vivo transcription studies [47], and transcriptosome studies [63] have been carried out. The different lineage-specific proteins were compared with microarray studies carried out by Nicholson et al. [63]. Of all the group-specific proteins identified in this work, 61 chlamydiae loci were determined to be regulated in this manner, and fall into one of the following 4 categories as divided by Nicholson et al. [63]): early (6-24 hours post infection (hpi)), midlate I (12-24 hpi), midlate II (18-24 hpi) or late (24-36 hpi). The results for the stagespecific expression of these proteins are summarized in Table 6. IncC, a Chlamydiaceae-specific protein, is the only identified ORF in this study to be expressed at the early time point. Of the midlate I expressed genes, all the Chlamydiales-specific proteins were hypothetical (CT053, CT066, СT273, СT504, СТ635, СТ666, СТ667, СТ670, CT734). Of the midlate I Chlamydiaceae-specific proteins, LtuA (CT377) and PmpB (CT413), Pmp F-I (CT870-2, CT874) were the only ORFs of known function, while others (CT289, СТ372, СТ618, СТ668, СТ671) remain to be understood. Interestingly, only Chlamydiaceae-specific molecules and 2 putatively lost/transferred genes were found to be expressed during the midlate II phase. These Chlamydiaceae-specific proteins consisted of the clustered loci CT412/413, as well as OmpA (CT681) and OmpB (CT713). The lost/transferred genes, CT049 and CT051, were hypothetical proteins of unknown function. Many temporally expressed chlamydiae-specific genes were found in the late phase of the developmental cycle. Of the Chlamydiales proteins, OmcA (CT444) and OmcB (CT443) were the only proteins of known function while the remaining 4 were hypothetical (СТ016, СТ017, CT181 and CT546). Several interesting proteins were expressed late in the Chlamydiaceae-specific category including HctB (СT046), LtuB (CT080), YprS (CT392), SRP (CT442), the clustered loci OmcA (CT444) and OmcB (CT443), PmpE (CT869) and the clustered loci CT578/579 and CT082/083. All other differentially expressed proteins during this phase were hypothetical regardless of chlamydial lineage; Chlamydiaceae (CT005, CT288, СТ365, СТ552, СТ565, СТ620, СТ695, СТ712, CT848), Chlamydia (CT249, CT694) and lost/transferred genes (CT050, CT214, CT702, CT868).

\section{Divergence rates of Chlamydiae-specific proteins}

We have also examined the sequence divergence rates for chlamydiae-specific proteins as compared to more ubiquitous proteins to determine whether the former proteins are evolving at a much faster rate. A relative measure of this was obtained by determining the degree of sequence conservation (as measured by \% amino acid identity) among different chlamydial species for a number of $\mathrm{Chl}$. trachomatis proteins that are either Chlamydiales-specific or which are more broadly distributed among bacteria. Results of these analysis for the two classes of proteins (i.e. Chlamydiales-specific vs broadly distributed) are presented in Tables 7A and 7B, respectively. As seen, in both cases, Chl. trachomatis proteins exhibited highest identity ( $75-$ $90 \%$ ) to the Chl. muridarum homologs. This was followed by the species from the Chlamydophila genus (41-62\% identity for the chlamydiae-specific proteins vs $60-80 \%$ identity for the broadly distributed group) and the $P$. amoebophila. The overall pattern that was observed was very similar for the two sets of proteins, although the proteins that are more broadly distributed were found to exhibit between $5-15 \%$ higher degree of conservation (i.e. slower rate of divergence) in comparison to the Chlamydiales-specific proteins.

\section{Conclusion}

Chlamydial species are among the 'high profile' pathogens of the $21^{\text {st }}$ century [1]. These species are responsible for a vast array of serious diseases in humans and animals. Our understanding of the chlamydial diversity, host range, environmental distribution, as well as clinical involvement is presently limited and significantly underestimated. In this work, we have determined a large number of proteins which are uniquely present in various known chlamydiae species at different taxonomic levels. The whole protein signatures that we have identified include 59 ORFs that are unique to various known Chlamydiales, 79 ORFs unique for the Chlamydiaceae family, 20 unique ORFs each for the Chlamydia and Chlamydo- 
phila genera, as well as 445 ORFs that are presently distinctive of the P. amoebophila (Table 8) The smaller numbers of unique ORFs that are found in the Chalmydiaceae species in comparison to the P. amoebophila may be related to their smaller genome sizes and also the fact that former species grow in a more stable niche as compared to the latter species [11]. Also, 31 cases of putatively lost genes from the different chlamydial genomes were detected. The simplest and most parsimonious explanation for these shared unique signature proteins is that they were introduced only once in a common ancestor of the indicated chlamydial taxonomic groups located at different phylogenetic depths and then vertically passed on to species that descended from that particular ancestor $[64,65]$. In our analysis, we have also found some examples of chlamydiae-specific proteins which show sporadic species distribution (e.g. present in only a few Chlamydia and Chlamydophila species, but not in other species from these genera). Such proteins could possibly arise from two different mechanisms. First, it is possible that such genes were introduced initially at a deeper phylogenetic level (i.e. order or family) and then selectively lost in some species from the latter branching taxa. Alternatively, their distribution can be explained if the gene in question was initially introduced in one chlamydia species and then laterally transferred to some others, as is the case for the nonmitochondrial ADP-ATP translocases $[59,60]$. The numbers of such proteins is relatively small in comparison to the proteins that show taxa specific distribution.

We have recently described a number of molecular signatures consisting of conserved indels (i.e. inserts and deletions) in widely distributed proteins viz. RNA polymerase $\alpha$ subunit, elongation factor-Tu, elongation factor-P, DNA gyrase B and lysyl-tRNA synthetase, that are distinctive characteristics of all chlamydial species [25]. The sequence information for these proteins was also obtained from Simkania negevensis, Waddlia chondrophila, and in a number of cases for Neochlamydia hartmanellae, covering all families within the Chlamydiae phylum. The unique presence of these conserved indels in all chlamydiae species provides strong evidence that they are distinctive characteristics of the entire Chlamydiales order. In phylogenetic trees based on a combined dataset of these protein sequence as well as 16S rRNA, the traditional Chlamydiaceae species (i.e. Chlamydophila and Chlamydia) and the chlamydiae-like organisms (viz. Simkania, Waddlia and Parachlamydia) were found to form two distinct clades indicating that these two groups have diverged from each other very early in the evolution of chlamydiae. The chlamydiae-specific proteins identified in the present work provide additional powerful means for understanding and constructing a reliable phylogeny of the Chlamydiales. Based upon the shared presence of these chlamydial-specific proteins, different taxonomic clades or groups within the Chlamydiales could be identified. Figure 1 shows a tree indicating branch points marked by the different chlamydiae group-specific proteins. In addition to distinguishing $P$. amoebophila from other Chlamydiaceae species, these proteins also support the distinctness of the two genera (i.e. Chlamydophila and Chlamydia) within this family. The phylogenetic inferences based on these proteins are in complete agreement with the relationships observed within this phylum based on different proteins as well as $16 \mathrm{~S}$ rRNA trees $[2,8,25]$. The genes encoding this set of peptides were likely acquired or evolved sometime after the divergence of the Protochlamydia and the other chlamydia-like organisms. Although sequence information for other chlamydiae (viz. Simkania and Waddlia) is lacking at present, it is likely that many of the Chlamydiales-specific proteins identified here will also be found in these species. Further, the clustering of the chlamydiaelike species in phylogenetic trees [2,25]suggests that many of the proteins which are presently indicated to be specific for $P$. amoebophila may also be found in the other chlamydiae-like organisms and they may provide unique molecular markers for these groups of species.

The analyses of bacterial genomes have indicated that a substantial proportion of their gene repertoire is comprised of signature proteins or ORFans i.e., open reading frames which have no known homologs and consequently no known function [64-66]. The mechanisms by which such novel genes arise in different genomes are presently not clearly understood and they have been discussed in other recent publications [67-69]. However, it is possible that homologs of some of these genes/proteins are also present in other bacteria but because of their extensive sequence divergence significant similarity to the chlamydiae homologs is not observed. One example where this may be the case is that of the OmcA (CT444) protein, which is listed as a Chlamydiaceae-specific protein in this study (Table 2). An OmcA homolog is annotated in $P$. amoebophila genome because it is cysteine-rich and upstream of a large cysteine-rich protein, but it does not show significant similarity to the Chlamydiaceae homologs in BLASTp searches. Another protein that we have not included in any of the Tables but is of interest is CT020 (signal peptidase I). The homologs of this protein are highly conserved in all chlamydiae ( $\mathrm{E}$ values ranging from 0 to $1 \mathrm{e}-101)$ and there is a large drop in $\mathrm{E}$ value from chlamydiae to the first non-chlamydiae hit (E value $3 \mathrm{e}-$ 09), which is also indicated as signal peptidase I. The sequence of this protein has again greatly diverged between chlamydiae and non-chlamydiae species. Although the presence of these proteins could be explained by extensive sequence divergence, the possibility that they may have originated independently cannot be excluded. Our survey of the divergence rates of proteins that are either specific for the Chlamydiales vs those that 
are broadly distributed in different bacteria, indicate that Chlamydiales-specific proteins exhibit only slightly higher divergence rate $(\sim 10 \%)$ in comparison to the more broadly distributed proteins. This difference in our view is unlikely to be generally responsible for the failure to detect the orthologs of most of the chlamydial-specific proteins in other species.

Most of the chlamydiae-specific proteins that have been identified in the present work are of unknown function. Many of these genes are present in distinct clusters in genomes indicating that these clusters could comprise functional units and the corresponding proteins may be involved in related cellular functions $[26,70]$. The studies aimed at understanding the cellular functions of the Chlamydiales-specific proteins (i.e. their localization, expression and function) should prove highly informative for understanding chlamydial development, virulence and infectivity. The studies on the Chlamydiaceae-specific proteins should provide important insights regarding characteristics that distinguish them from other chlamydiae families. Additionally, a large number of protein coding sequences that are specific for either particular genera or different chlamydial species have been identified. The functional studies of such proteins could provide important information regarding factors, which are presumably responsible for their different properties such as tissue tropism and disease spectrum.

The identified chlamydiae-specific proteins also provide novel biomarkers that should prove of much value in the diagnosis of these bacteria and in exploration of their prevalence and diversity. The identification and screening of chlamydiae and chlamydiae-like organisms in the past has relied on a small number of biomarkers (e.g. 16S and $23 S$ rRNA, MOMP, GroEL protein, lipopolysaccharide epitope Kdo, small cysteine-rich lipoprotein and 60-kDa cysteine-rich protein) [71-74]. In this context, our identification of numerous proteins, which are uniquely found in either various Chlamydiales, Chlamydiaceae, Chlamydophila or Chlamydia groups of species is of great interest and they provide novel and valuable means for detection of these groups of species. Many of these group-specific proteins are highly conserved and sequence alignment for one Chlamydiales-specific protein (CT429) and one Chlamydiaceae-specific protein (CT712) are presented in Figure 2. The sequence alignments of both these proteins contain many highly conserved regions that are suitable for design of PCR primers that should enable successful amplification of all species belonging to these groups. Monoclonal and polyclonal antibodies based upon different chlamydial-specific proteins provide another means for diagnostic studies. Thus, based upon different groupspecific proteins that have been identified in the present work, it should be possible to develop novel diagnostics that are capable of distinguishing different groups of chlamydiae species (viz. Chlamydia, Chlamydophila, Chlamydiaceae and Chlamydiales) from each other with high degree of accuracy.

\section{Methods \\ Identification of Chlamydiae-specific proteins}

In order to identify proteins which are chlamydiae-specific, systematic BLAST searches were carried out on different proteins in the genomes of Chl. trachomatis and Chlam. caviae against all available sequences in the databases. BLASTp searches were performed using each of the proteins or ORFs in these genomes as probes to identify all other bacteria which contain related protein sequences [75]. The searches were carried out using default search parameters, as set by the protein-protein BLAST program, which included the low complexity filter. The low complexity filter removes regions of query sequence which are highly repetitive and which could lead to spurious high similarity with unrelated proteins. The results obtained were visually inspected for homologs showing specificity to the chlamydiae with no other similar homologs present in any other bacteria. This was done by analyzing expect values (E values) for all proteins. The Expect value (E value) represents the statistical significance of a hit in a BLAST search. This number equates to the number of hits that one would find by chance when searching a database of a particular size. The $\mathrm{E}$ values depend upon the length of the protein as well as the extent of sequence homology that is observed with any given protein. The E values which are very low (generally less than e-200) are indicated in the results obtained as ' 0 '. In our extensive work, the $\mathrm{E}$ value for the top hit (i.e. to the query itself) is generally found to be ' 0 ', when the query protein is of a length longer than 325 aa. For proteins of smaller lengths, the $\mathrm{E}$ value for the top hit has a finite value. The $\mathrm{E}$ value of top hits may be slightly affected by the application of the filter which effectively shortens the query length [75]. Proteins were considered Chlamydiales-specific if all hits belonged to the chlamydiae species, or if the next best non-chlamydiae hit had an expect value which was not significant and could occur by chance. BLAST results with $\mathrm{E}$ values $>10^{-4}$ are in range where the observed similarity could occur by chance. All such hits were examined for protein lengths to ensure that it was similar to that of the query protein before it was considered as a related protein. Occasionally higher E-values were permitted in analysis when the length of the query protein was small as with fewer characters the $\mathrm{E}$ values are higher and this often produce hits with higher E-values (i.e. $>10^{-4}$ ) that are significant for the study. It should be mentioned that BLAST searches can sometime indicate misleading relationships, particularly when no close relatives of the query species are in the database [76]. However, in the present study where most of the reported BLAST hits are for chlamydiae species, for 
which there are several published genome, such a possibility is highly unlikely. For all chlamydiae-specific proteins, E-values for each chlamydiae BLAST hit, as well as the first non-chlamydial hit are reported here. Furthermore, the sizes of each protein in Chl. trachomatis (or other genomes that were used as BLAST probes) are also listed, and the sizes of other chlamydial homologs are highly similar, unless it is otherwise stated. The same criteria were used for the detection of Chlamydiaceae-specific, Chlamydia-specific and Chlamydophila-specific proteins. For clarification purposes, the chlamydiae loci and accession numbers are given as reference for the different proteins. The genome of $P$. amoebophila was also examined in this manner to identify proteins that are specific for Protochlamydia. Those genes which were found in all species within a given group (i.e. Chlamydiales, Chlamydiaceae etc) except for one or a few species, were considered to be due to gene loss or lateral gene transfer.

\section{Alignments of Chlamydiae-specific proteins and percentage identity determination}

The global alignments of Chlamydiales-specific protein CT429 and Chlamydiaceae-specific protein CT712 were carried out by first retrieving chlamydiae sequences from the NCBI database [77] in FASTA format. ClustalX program [78] was then used to construct both alignments using the default parameters. Pair-wise alignments of sequences for determining percentage identity between Chl. trachomatis proteins and those from other chlamydial species were carried out using the ALIGN Plus 4 program package (Scientific and Educational Software) using the BLOSUM 62 scoring matrix [79] and the default parameters of the alignment program.

\section{Analysis of temporal expression of Chlamydiae-specific proteins}

Lineage-specific chlamydial proteins were compared to the microarray data of Nicholson et al. [63]. In that work, the expression patterns of Chl. trachomatis genes were divided into different stages: early (6-24 hours post infection), midlate I (12-24 hpi), midlate II (18-24 hpi) or late (24-36 hpi). Proteins identified in that work which exhibited at least 3-fold differences in expression patterns at different stages, were then placed into one of these different groups. The information for stage-specific expression of chlamydiae-specific proteins was extracted from this study.

\section{Authors' contributions}

MSV was assigned to carry out the initial BLAST searches on Chl. trachomatis and Chlam. pneumoniae genomes to identify chlamydial specific proteins. Subsequently, EG was asked to confirm these results and she also carried out BLAST searches on Protochlamydia proteins to identify proteins that are unique to this species. EG also prepared an initial draft of the manuscript. RSG was responsible for conceiving and directing this study from the beginning to the end, for the final evaluation of all results, and for preparing the final submitted manuscript. All authors have read and approved the final manuscript.

\section{Acknowledgements}

The work was supported by a research grant from the Canadian Institute of Health Research.

\section{References}

I. Kalayoglu MV, Byrne GI: Chlamydia. In The Prokaryotes: An Evolving Electronic Resource for the Microbiological Community, 3rd edition, release 3.7, http:/link.springer-ny.com/link/service/books/lOI25/. 3rd edition. Edited by: Dworkin M. New York, Springer-Verlag; 2001.

2. Everett KD, Bush RM, Andersen AA: Emended description of the order Chlamydiales, proposal of Parachlamydiaceae fam. nov. and Simkaniaceae fam. nov., each containing one monotypic genus, revised taxonomy of the family Chlamydiaceae, including a new genus and five new species, and standards for the identification of organisms. Int J Syst Bacteriol 1999, $49 \mathrm{Pt}$ 2:415-440.

3. Rurangirwa FR, Dilbeck PM, Crawford TB, McGuire TC, McElwain TF: Analysis of the I6S rRNA gene of micro-organism WSU 86-1044 from an aborted bovine foetus reveals that it is a member of the order Chlamydiales: proposal of Waddliaceae fam. nov., Waddlia chondrophila gen. nov., sp. nov. Int J Syst Bacteriol 1999, 49 Pt 2:577-58I.

4. Everett KD: Chlamydia and Chlamydiales: more than meets the eye. Vet Microbiol 2000, 75:109-126.

5. Kahane S, Greenberg D, Friedman MG, Haikin H, Dagan R: High prevalence of "Simkania Z," a novel Chlamydia-like bacterium, in infants with acute bronchiolitis. J Infect Dis 1998, 177:| 1425-|429.

6. Horn M, Wagner M, Muller KD, Schmid EN, Fritsche TR, Schleifer KH, Michel R: Neochlamydia hartmannellae gen. nov., sp. nov. (Parachlamydiaceae), an endoparasite of the amoeba Hartmannella vermiformis. Microbiology 2000, I 46 ( Pt 5): | 23 |- 1239.

7. Corsaro D, Venditti D: Emerging chlamydial infections. Crit Rev Microbiol 2004, 30:75-106.

8. Corsaro D, Valassina M, Venditti D: Increasing diversity within Chlamydiae. Crit Rev Microbiol 2003, 29:37-78.

9. Horn M, Wagner M: Evidence for additional genus-level diversity of Chlamydiales in the environment. FEMS Microbiol Lett 200I, 204:7I-74.

10. Fritsche TR, Horn M, Wagner M, Herwig RP, Schleifer KH, Gautom RK: Phylogenetic diversity among geographically dispersed Chlamydiales endosymbionts recovered from clinical and environmental isolates of Acanthamoeba spp. Appl Environ Microbiol 2000, 66:2613-2619.

II. Horn M, Collingro A, Schmitz-Esser S, Beier CL, Purkhold U, Fartmann B, Brandt P, Nyakatura GJ, Droege M, Frishman D, Rattei T, Mewes HW, Wagner M: Illuminating the evolutionary history of chlamydiae. Science 2004, 304:728-730.

12. Greub G, Raoult D: Parachlamydiaceae: potential emerging pathogens. Emerg Infect Dis 2002, 8:625-630.

13. Stephens RS, Kalman S, Lammel C, Fan J, Marathe R, Aravind L, Mitchell W, Olinger L, Tatusov RL, Zhao Q, Koonin EV, Davis RW: Genome sequence of an obligate intracellular pathogen of humans: Chlamydia trachomatis. Science 1998, 282:754-759.

14. Read TD, Brunham RC, Shen C, Gill SR, Heidelberg JF, White O, Hickey EK, Peterson J, Utterback T, Berry K, Bass S, Linher K, Weidman J, Khouri H, Craven B, Bowman C, Dodson R, Gwinn M, Nelson W, DeBoy R, Kolonay J, McClarty G, Salzberg SL, Eisen J, Fraser CM: Genome sequences of Chlamydia trachomatis MoPn and Chlamydia pneumoniae AR39. Nucleic Acids Res 2000, 28: 1397-1406.

15. Read TD, Myers GS, Brunham RC, Nelson WC, Paulsen IT, Heidelberg J, Holtzapple E, Khouri H, Federova NB, Carty HA, Umayam LA, Haft DH, Peterson J, Beanan MJ, White O, Salzberg SL, Hsia RC, McClarty G, Rank RG, Bavoil PM, Fraser CM: Genome sequence of Chlamydophila caviae (Chlamydia psittaci GPIC): examin- 
ing the role of niche-specific genes in the evolution of the Chlamydiaceae. Nucleic Acids Res 2003, 31:2 I34-2147.

16. Thomson NR, Yeats C, Bell K, Holden MT, Bentley SD, Livingstone M, Cerdeno-Tarraga AM, Harris B, Doggett J, Ormond D, Mungall K, Clarke K, Feltwell T, Hance Z, Sanders M, Quail MA, Price C, Barrell BG, Parkhill J, Longbottom D: The Chlamydophila abortus genome sequence reveals an array of variable proteins that contribute to interspecies variation. Genome Res 2005, 1 5:629-640.

17. Collingro A, Toenshoff ER, Taylor MW, Fritsche TR, Wagner M, Horn M: 'Candidatus Protochlamydia amoebophila', an endosmbiont of Acanthamoeba spp. Int J Syst Evol Microbiol 2005, 55: $1863-1866$

18. Kalman S, Mitchell W, Marathe R, Lammel C, Fan J, Hyman RW, Olinger L, Grimwood J, Davis RW, Stephens RS: Comparative genomes of Chlamydia pneumoniae and C. trachomatis. Nat Genet 1999, $21: 385-389$.

19. Griffiths E, Gupta RS: Protein signatures distinctive of chlamydial species: horizontal transfers of cell wall biosynthesis genes glmU from archaea to chlamydiae and murA between chlamydiae and Streptomyces. Microbiology 2002 I 48:254|-2549.

20. Gupta RS: Protein phylogenies and signature sequences: A reappraisal of evolutionary relationships among archaebacteria, eubacteria, and eukaryotes. Microbiol Mol Biol Rev 1998 , 62:|435-|49|.

21. Gupta RS: Protein signatures distinctive of Alpha proteobacteria and its subgroups and a model for Alpha proteobacterial evolution. Crit Rev Microbiol 2005, 3 I : I 35.

22. Gupta RS, Griffiths E: Critical issues in bacterial phylogeny. Theor Popul Biol 2002, 61:423-434.

23. Griffiths $E$, Gupta RS: The use of signature sequences in different proteins to determine the relative branching order of bacterial divisions: evidence that Fibrobacter diverged at a similar time to Chlamydia and the Cytophaga-Flavobacterium-Bacteroides division. Microbiology 200I, I 47:26I I-2622.

24. Gupta Lab's Bacterial Phylogeny Website:http://www.bacterialphylogeny.com. http://www bacterialphylogeny com 2005.

25. Griffiths E, Petrich A, Gupta RS: Conserved Indels in Essential Proteins that are Distinctive Characteristics of Chlamydiales and provide novel means for their identification. Microbiology 2005, I 5 I:2647-2657.

26. Doerks T, von Mering C, Bork P: Functional clues for hypothetical proteins based on genomic context analysis in prokaryotes. Nucleic Acids Res 2004, 32:632I-6326.

27. Koehler JE, Birkelund S, Stephens RS: Overexpression and surface localization of the Chlamydia trachomatis major outer membrane protein in Escherichia coli. Mol Microbiol 1992 , 6:1087-1094.

28. Everett KD, Hatch TP: Architecture of the cell envelope of Chlamydia psittaci 6BC. J Bacteriol 1995, 177:877-882.

29. Hatch TP: Disulfide cross-linked envelope proteins: the functional equivalent of peptidoglycan in chlamydiae? I Bacteriol 1996, I 78: I-5

30. Weisburg WG, Hatch TP, Woese CR: Eubacterial origin of chlamydiae. I Bacteriol 1986, 167:570-574.

3I. Staley JT, Fuerst JA, Giovannoni S, Schlesner H: The order Planctomycetales and the genera Planctomyces, Pirellula, Gemmata and Isosphaera. In The Prokaryotes Volume I. 2nd edition. Edited by: Balows A, Truper HG, Dworkin M, Harder W and Schleifer KH. New York, Springer-Verlag; | 992:37| 0-373|.

32. Ward NL, Rainey FA, Hedlund BP, Staley JT, Ludwig W, Stackebrandt $\mathrm{E}$ : Comparative phylogenetic analyses of members of the order Planctomycetales and the division Verrucomicrobia: 23S rRNA gene sequence analysis supports the I6S rRNA gene sequence-derived phylogeny. International Journal of Systematic Bacteriology 2000, 50:1965-1972.

33. Bateman $A$, Bycroft $M$ : The structure of a LysM domain from $E$. coli membrane-bound lytic murein transglycosylase $D$ (MltD). I Mol Biol 2000, 299: I | 3-I I I9.

34. Ghuysen JM, Goffin C: Lack of cell wall peptidoglycan versus penicillin sensitivity: new insights into the chlamydial anomaly. Antimicrob Agents Chemother 1999, 43:2339-2344.

35. Fox A, Rogers JC, Gilbart J, Morgan S, Davis CH, Knight S, Wyrick PB: Muramic acid is not detectable in Chlamydia psittaci or
Chlamydia trachomatis by gas chromatography-mass spectrometry. Infect Immun 1990, 58:835-837.

36. Vandahl BB, Birkelund S, Christiansen G: Genome and proteome analysis of Chlamydia. Proteomics 2004, 4:283I-2842.

37. Fields KA, Mead DJ, Dooley CA, Hackstadt T: Chlamydia trachomatis type III secretion: evidence for a functional apparatus during early-cycle development. Mol Microbiol 2003, 48:67I-683.

38. Rockey DD, Lenart J, Stephens RS: Genome sequencing and our understanding of chlamydiae. Infect Immun 2000, 68:5473-5479.

39. Hatch T: Chlamydia: old ideas crushed, new mysteries bared. Science 1998, 282:638-639.

40. NCBI Conserved Domain (YjgP_YjgQ) Website:http:// www.ncbi.nlm.nih.gov/Structure/cdd/ cddsrv.cgi?uid=pfam03739\&version=v2.03. 2006

4I. Ceccarelli EA, Arakaki AK, Cortez N, Carrillo N: Functional plasticity and catalytic efficiency in plant and bacterial ferredoxin-NADP(H) reductases. Biochim Biophys Acta 2004, 1698: I55-165.

42. Kaul R, Hoang A, Yau P, Bradbury EM, Wenman WM: The chlamydial EUO gene encodes a histone $\mathrm{HI}$-specific protease. J Bacteriol 1997, 179:5928-5934.

43. Zhang L, Douglas AL, Hatch TP: Characterization of a Chlamydia psittaci DNA binding protein (EUO) synthesized during the early and middle phases of the developmental cycle. Infect Immun 1998, 66:1167-1173.

44. Barry CEIII, Brickman TJ, Hackstadt T: Hcl-mediated effects on DNA structure: a potential regulator of chlamydial development. Mol Microbiol 1993, 9:273-283.

45. Thomas NS, Lusher M, Storey CC, Clarke IN: Plasmid diversity in Chlamydia. Microbiology 1997, I43 ( Pt 6): | 847-1854.

46. Comanducci M, Ricci S, Cevenini R, Ratti G: Diversity of the Chlamydia trachomatis common plasmid in biovars with different pathogenicity. Plasmid 1990, 23:149-154.

47. Fahr MJ, Douglas AL, Xia W, Hatch TP: Characterization of late gene promoters of Chlamydia trachomatis. J Bacteriol 1995 , 177:4252-4260.

48. Tanzer RJ, Hatch TP: Characterization of outer membrane proteins in Chlamydia trachomatis LGV serovar L2. I Bacteriol 200I, 183:2686-2690.

49. Kaltenboeck B, Kousoulas KG, Storz J: Structures of and allelic diversity and relationships among the major outer membrane protein (ompA) genes of the four chlamydial species. J Bacteriol 1993, 175:487-502.

50. Starnbach MN, Loomis WP, Ovendale P, Regan D, Hess B, Alderson MR, Fling SP: An inclusion membrane protein from Chlamydia trachomatis enters the MHC class I pathway and stimulates a CD8+ T cell response. J Immunol 2003, I71:4742-4749.

5I. Kawa DE, Schachter J, Stephens RS: Immune response to the Chlamydia trachomatis outer membrane protein PorB. Vaccine 2004, 22:4282-4286.

52. Rockey DD, Scidmore MA, Bannantine JP, Brown WJ: Proteins in the chlamydial inclusion membrane. Microbes Infect 2002, 4:333-340.

53. Hackstadt T, Fischer ER, Scidmore MA, Rockey DD, Heinzen RA: Origins and functions of the chlamydial inclusion. Trends Microbiol 1997, 5:288-293.

54. Bannantine JP, Rockey DD, Hackstadt T: Tandem genes of Chlamydia psittaci that encode proteins localized to the inclusion membrane. Mol Microbiol 1998, 28:1017-1026.

55. Sappington TW, Raikhel AS: Ligand-binding domains in vitellogenin receptors and other LDL-receptor family members share a common ancestral ordering of cysteine-rich repeats. J Mol Evol 1998, 46:476-487.

56. Scidmore-Carlson MA, Shaw El, Dooley CA, Fischer ER, Hackstadt T: Identification and characterization of a Chlamydia trachomatis early operon encoding four novel inclusion membrane proteins. Mol Microbiol 1999, 33:753-765.

57. Bush RM, Everett KD: Molecular evolution of the Chlamydiaceae. Int J Syst Evol Microbiol 200 I, 5 I:203-220.

58. Garner SA, Everson JS, Lambden PR, Fane BA, Clarke IN: Isolation, molecular characterisation and genome sequence of a bacteriophage (Chp3) from Chlamydophila pecorum. Virus Genes 2004, 28:207-2। 4 .

59. Brinkman FS, Blanchard JL, Cherkasov A, Av-Gay Y, Brunham RC, Fernandez RC, Finlay BB, Otto SP, Ouellette BF, Keeling PJ, Rose AM, 
Hancock RE, Jones SJ, Greberg $\mathrm{H}$ : Evidence that plant-like genes in Chlamydia species reflect an ancestral relationship between Chlamydiaceae, cyanobacteria, and the chloroplast. Genome Res 2002, I 2: I I59-I I67.

60. Greub G, Raoult D: History of the ADPIATP-translocaseencoding gene, a parasitism gene transferred from a Chlamydiales ancestor to plants I billion years ago. Appl Environ Microbiol 2003, 69:5530-5535.

61. Zhong J, Douglas AL, Hatch TP: Characterization of integration host factor (IHF) binding upstream of the cysteine-rich protein operon (omcAB) promoter of Chlamydia trachomatis LGV serovar L2. Mol Microbiol 200 I, 4 I:45I-462.

62. Newhall WJ: Biosynthesis and disulfide cross-linking of outer membrane components during the growth cycle of Chlamydia trachomatis. Infect Immun 1987, 55:162-168.

63. Nicholson TL, Olinger L, Chong K, Schoolnik G, Stephens RS: Global stage-specific gene regulation during the developmental cycle of Chlamydia trachomatis. I Bacteriol 2003, I 85:3179-3189.

64. Daubin $\mathrm{V}$, Ochman $\mathrm{H}$ : Bacterial genomes as new gene homes: the genealogy of ORFans in E. coli. Genome Res 2004, 14:1036-1042.

65. Kainth P, Gupta RS: Signature proteins that are distinctive of alpha proteobacteria. BMC Genomics 2005, 6:94.

66. Siew N, Fischer D: Twenty thousand ORFan microbial protein families for the biologist? Structure (Camb) 2003, I I:7-9.

67. Daubin V, Lerat E, Perriere G: The source of laterally transferred genes in bacterial genomes. Genome Biol 2003, 4:R57.

68. Lerat E, Daubin V, Ochman H, Moran NA: Evolutionary Origins of Genomic Repertoires in Bacteria. PLoS Biol 2005, 3: el 30 .

69. Frost LS, Leplae R, Summers AO, Toussaint A: Mobile genetic elements: the agents of open source evolution. Nat Rev Microbio 2005, 3:722-732

70. Suyama M, Bork P: Evolution of prokaryotic gene order: genome rearrangements in closely related species. Trends Genet 2001, 17:10-13.

7I. Everett KD, Hornung LJ, Andersen AA: Rapid detection of the Chlamydiaceae and other families in the order Chlamydiales: three PCR tests. J Clin Microbiol 1999, 37:575-580.

72. Sachse K, Grossmann E, Jager C, Diller R, Hotzel H: Detection of Chlamydia suis from clinical specimens: comparison of $P C R$, antigen ELISA, and culture. I Microbiol Methods 2003, 54:233-238.

73. Mardh PA: Chlamydia screening--yes, but of whom, when, by whom, and with what? Ann N Y Acad Sci 2000, 900:286-292.

74. Watson EJ, Templeton A, Russell I, Paavonen J, Mardh PA, Stary A, Pederson BS: The accuracy and efficacy of screening tests for Chlamydia trachomatis: a systematic review. I Med Microbiol 2002, 51 : 102I-1031.

75. Altschul SF, Madden TL, Schaffer AA, Zhang J, Zhang Z, Miller W, Lipman D]: Gapped BLAST and PSI-BLAST: a new generation of protein databases search programs. Nucleic Acids Research 1997 , 25:3389-3402

76. Koski LB, Golding GB: The closest BLAST hit is often not the nearest neighbor. J Mol Evol 200I, 52:540-542.

77. National Center for Biotechnology Information (NCBI) Website [http://www.ncbi.nlm.nih.gov/]. 2005

78. Thompson JD, Higgins DG, Gibson TJ: CLUSTAL W: improving the sensitivity of progressive multiple sequence alignment through sequence weighting, position-specific gap penalties and weight matrix choice. Nucleic Acids Res 1994, 22:4673-4680.

79. Henikoff S, Henikoff JG: Amino acid substitution matrices from protein blocks. Proc Natl Acad Sci U S A 1992, 89:10915-10919.

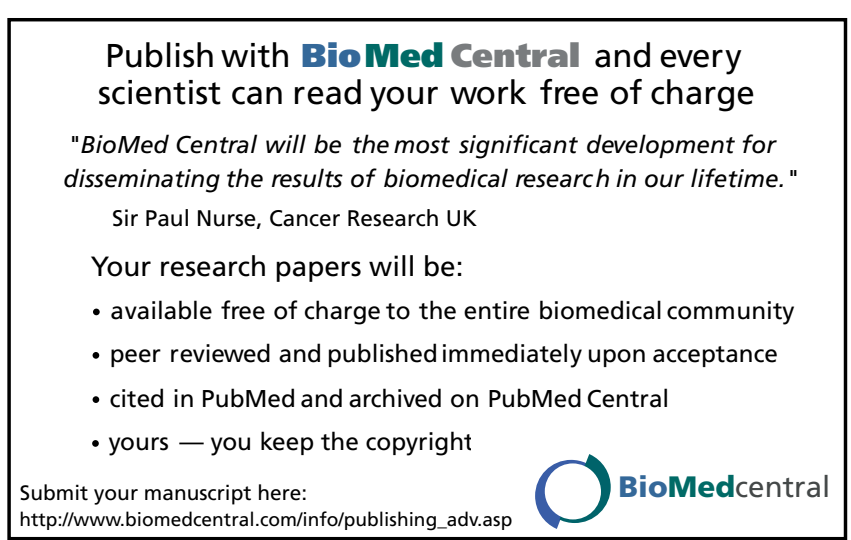

Page 20 of 20 